Chapter 1

\title{
Equal-Channel Angular Pressing and Creep in Ultrafine- Grained Aluminium and Its Alloys
}

\author{
Vaclav Sklenicka, Jiri Dvorak, Milan Svoboda, \\ Petr Kral and Marie Kvapilova \\ Additional information is available at the end of the chapter
}

http://dx.doi.org/10.5772/51242

\section{Introduction}

Creep strength and ductility are the key creep properties of creep-resistant materials but these properties typically have opposing characteristics. Thus, materials with conventional grain sizes may be strong or ductile but there are rarely both. In this connection, recent findings of high strength and good ductility in several submicrometer metals and alloys are of special interest [1]. Reduction of the grain size of a polycrystalline material can be successfully produced through advanced synthesis processes such as the electrodeposition technique [2] and severe plastic deformation SPD [1,3-6]. Although creep is an exceptionally old area of research, above mentioned processing techniques have become available over the last two decades which provide an opportunity to expand the creep behaviour into new areas that were not feasible in earlier experiments. Creep testing of nanocrystalline (grain size $\mathrm{d}<100 \mathrm{~nm}$ ) and ultrafine-grained $(\mathrm{d}<1 \mu \mathrm{m})$ materials is characterized by features that may be different from those documented for coarse-grained materials and thus cannot easily be compared.

Processing through the application of severe plastic deformation (SPD) is now an accepted procedure for producing bulk ultrafine-grained materials having grain sizes in the submicrometer or nanometer range. The use of SPD enhances certain material properties through the introduction of an ultrafine-grained microstructure. The ultrafine size of the grains in the bulk materials generally leads to significantly improved properties by comparison with polycrystalline materials having conventional grain sizes of the same chemical composition. Several SPD processing techniques are currently available but the most attractive technique is equalchannel angular pressing (ECAP), where the sample is pressed through a die constrained within a channel bent through an abrupt angle [4]. There are numerous reports of the processing of various pure metals and metallic alloys by ECAP and many of these reports involve a charac- 
terization of the microstructure and an investigation of the mechanical properties at ambient temperatures. There are also several reports of the tensile properties of the as-pressed materials at elevated temperatures with a special emphasis on the potential for achieving high superplastic elongations. However, the tests at elevated temperatures are invariably conducted under conditions of constant strain rate and, by contrast, only very limited reports are available describing the creep behaviour of aluminium and some aluminium alloys. Furthermore, the results for high-purity aluminium, which are the most extensive available to date, appear anomalous because under some testing conditions of stress and temperature the measured minimum or steady-state creep rates in the pressed materials with ultrafine grain sizes where slower than in the same material in a coarse-grained unpressed condition.

This chapter was initiated to provide basic information on the creep behaviour and microstructural characteristics of aluminium and some aluminium alloys. The chapter has arisen in connection with long-term research activity of the Advanced High Temperature Materials Group at the Institute of Physics of Materials, Academy of Sciences of the Czech Republic in Brno, Czech Republic. Thus, the objective of this chapter is to present an overview of some results of our current research in creep behaviour and a link between the microstructure and the creep properties of ultrafine-grained aluminium based alloys. Throughout the text, our results are compared with theoretical models and relevant experimental observations published in the literature.

\section{The development of processing using equal-channel angular pressing (ECAP)}

Processing by severe plastic deformation (SPD) may be defined as those metal forming procedures in which a very high strain is imposed on a bulk solid without the introduction of any significant change in the overall dimensions of the solid and leading to the production of exceptional grain refinement to that the processed bulk solids have 1000 or more grains in section [4]. Of a wide diversity of new SPD procedures, equal-channel angular pressing (ECAP) is an especially attractive processing technique. It is relatively simple procedure which can be applied to fairly large billets of many materials ranging from pure metals to precipitation-hardened alloys, intermetallics and metal-matrix composites.

\subsection{Principles of ECAP}

The principle of ECAP is illustrated schematically in Figure 1. For the die shown in Figure 1, the internal channel is bent through an abrupt angle, $\Phi$, and there is an additional angle, $\Psi$, which represents outer arc of curvature where the two channels intersect. The sample, in the form of a rod or bar, is machined to fit within channel and the die is placed in some form of fuss so that the sample can be pressed through the die using a plunger. The nature of the imposed deformation is simple shear which occurs as the billet passes through the die. The retention of the same cross-sectional area when processing by ECAP, despite the introduction of very large strains, is the important characteristic of SPD processing and it is charac- 
teristic which distinguishes this type of processing from conventional metal-working operations such as rolling, extrusion and drawing. Since the cross-sectional area remains unchanged, the same billet may be pressed repetitively to attain exceptionally high strain.
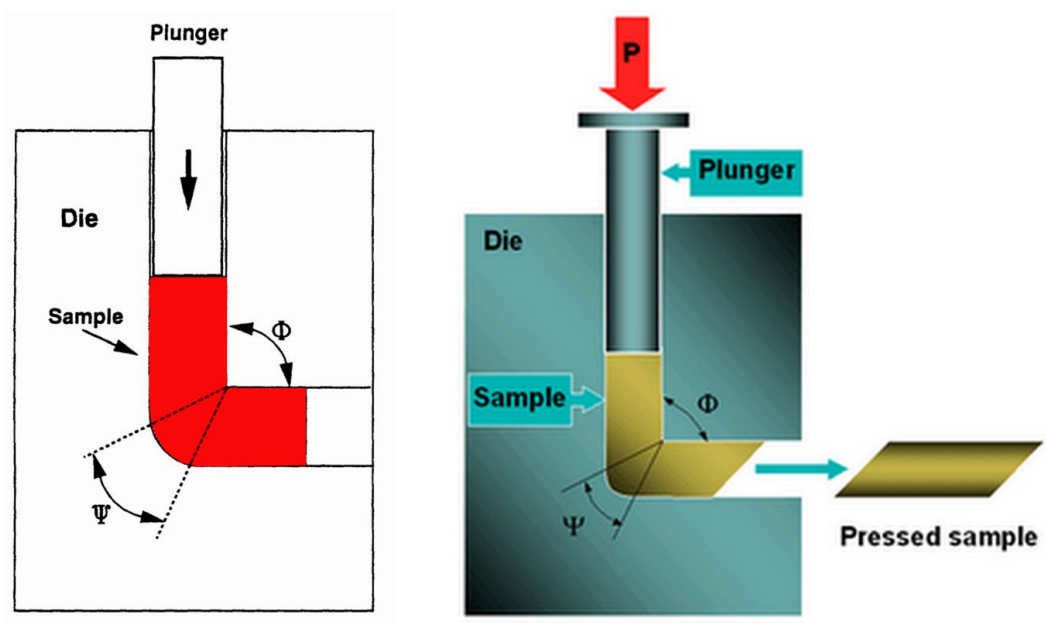

Figure 1. Principle of ECAP.

Aluminium and its alloys used in this investigation were pressed using an experimental facility for ECAP installed in the Institute of Physics of Materials, Academy of Sciences of the Czech Republic (Figure 2). The die was placed on a testing machine Zwick. ECAP was conducted mostly at room temperature with a die that had internal angle $90^{\circ}$ between two parts of the channel and an outer arc of curvature of $\sim 20^{\circ}$, where these two parts intersect. It can be shown from first principles that these angles lead to an imposed strain of $\sim 1$ in each passage of the sample. The ECAP die involved the use of billets of the length of $\sim 50-60 \mathrm{~mm}$ with square cross-section of $10 \mathrm{~mm} \times 10 \mathrm{~mm}$. The velocity of plunger was $10 \mathrm{~mm} / \mathrm{min}$.

\subsection{The processing routes in ECAP}

The use of repetitive pressing provides an opportunity to invoke different slip systems on each consecutive pass by simply rotating the samples in different ways. The four different processing routes are summarized schematically in Figure 3 [7]. In route A the sample is pressed without rotation, in route $B_{A}$ the sample is rotated by $90^{\circ}$ in alternate directions between consecutive passes, in route $B_{C}$ the sample is rotated by $90^{\circ}$ in the same sense (either clockwise or counter clockwise) between each pass and in route $C$ the sample is rotated by $180^{\circ}$ between passes. The distinction between these routes and the difference in number of ECAP passes may lead to variations both in the macroscopic distortions of the individual grains [8] and in the capability to develop a reasonably homogeneous and equiaxed ultrafine-grained microstructure. 


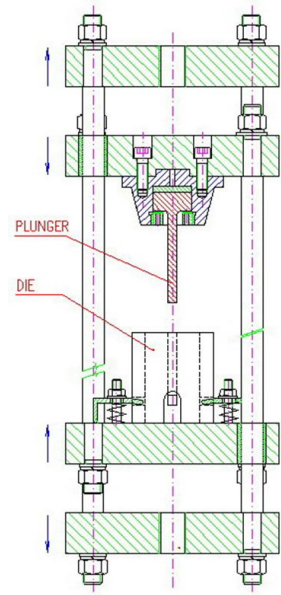

(a)

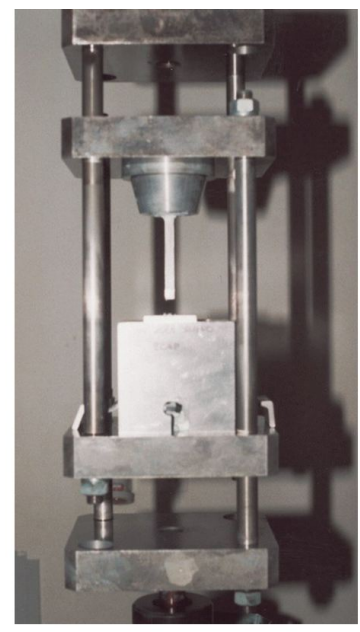

(b)

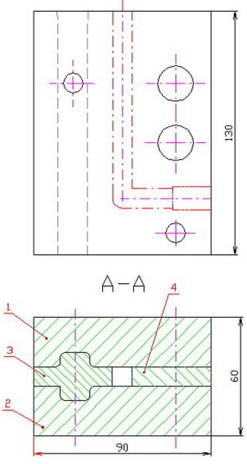

(c)

Figure 2. Adaptation of testing ZWICK machine for ECAP pressing $(a, b)$, and (c) sketch of ECAP die design.
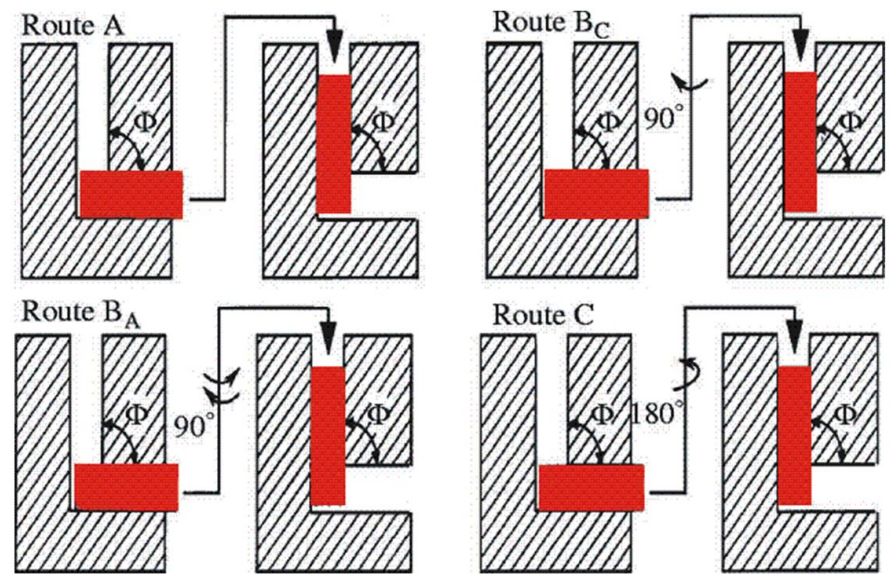

Figure 3. Schematic of four ECAP routes for repetitive pressing.

In this work the ECAP pressing was conducted in such a way that one or repetitive pressing was conducted followed either route $A, B$ (route $B_{C}$ was used only) or $C$. Detailed examinations of the effect of different processing routes showed that route $B_{C}$ leads to the most rapid evolution into an array of high-angle grain boundaries $[9,10]$. The result is explained by considering the shearing patterns developed in the samples during each processing route. Thus, 
the route $\mathrm{B}_{\mathrm{C}}$ is most probably the optimum ECAP processing route at least for the pressing of pure aluminium and its alloys [4].

\subsection{Mechanical properties and defects achieved using ECAP}

During the last two decades it has been demonstrated that an ultrafine-grained structure of materials processed by ECAP may lead to significantly higher strength and hardness but to a reduction in the ductility [4]. In this connection after ECAP the mechanical properties were tested mostly at room temperature using a testing machine operating at a constant rate of $2.0 \times 10^{-4} \mathrm{~s}^{-1}$ of crosshead displacement.

\subsubsection{Tensile properties}

Tensile tests were conducted at $293 \mathrm{~K}$ on pure aluminium after processing by ECAP for samples after different number of ECAP passes. In limited extent mechanical tests were performed on the samples after ECAP and static annealing at $473 \mathrm{~K}$ [11]. In Figure 4 the tensile data are summarized as a function of the number of passes. It is apparent from these figures that a very significant increase in yield and ultimate tensile stress occurred after the first pressing. The subsequent pressing further increased yield and ultimate stress values but to a lower rate. Further, a saturation of the level of both the parameters was attained after four passes.
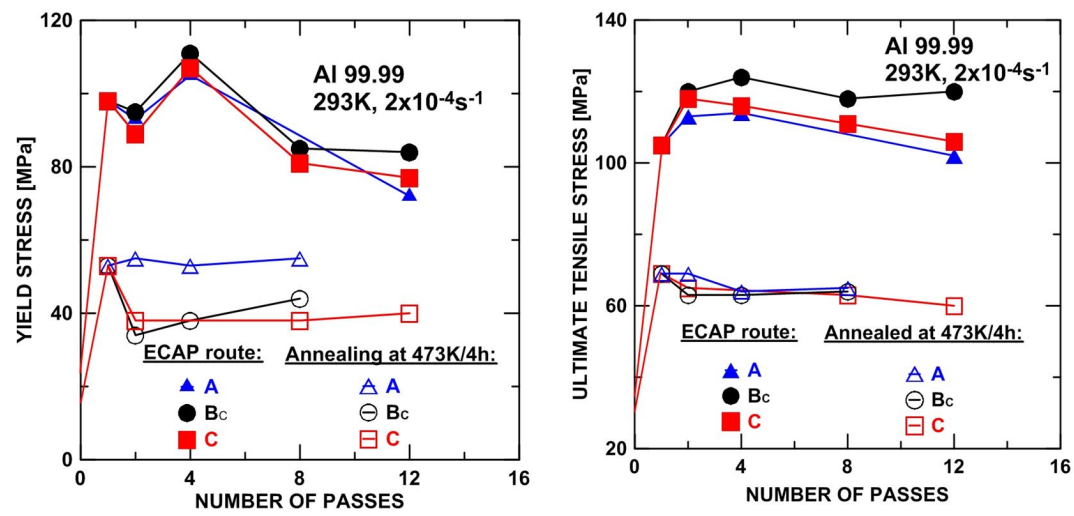

Figure 4. Influence of different ECAP routes and different number of ECAP passes on (a) yield stress, and (b) ultimate tensile stress after static annealing.

From Figure 4 it can be also noticed that static annealing at $473 \mathrm{~K}$ leads to a substantial decrease in the level of yield and ultimate tensile stress values due to diffusion based recovery processes for all the ECAP processed samples. No significant differences in mechanical properties among the ECAP process routes examined were found. Further, from Figure 4 is clear that although the levels of the tensile data for ECAPed Al highly decrease with the number of ECAP passes, the stress levels after 8 passes are much higher than the stress levels in the annealing state and these differences come to more than twice. This result indi- 
cates that, when compared with the tensile behaviour of the annealed state, the flow stress is considerably improved through the application of ECAP [11,12].

\subsubsection{Hardness measurements}

Figure 5a shows Vickers microhardness plotted against the number of ECAP passes for extremely high purity aluminium (99.99\%) [12]. The hardness increases up to two passes to take a maximum due to the very high dislocation density. However, subsequent passes lead to a decrease in the hardness because many of the subgrain boundaries evolve into high-angle grain boundaries. Figure $5 \mathrm{~b}$ shows Vickers microhardness plotted against different periods of time of a static annealing at $473 \mathrm{~K}$ for pure $(99.99 \%)$ Al processed by ECAP by two different processing routes. A pronounced decrease of microhardness with an increase of annealing time can be explained by significant grain growth and softening of pressed material during an annealing exposures [11].
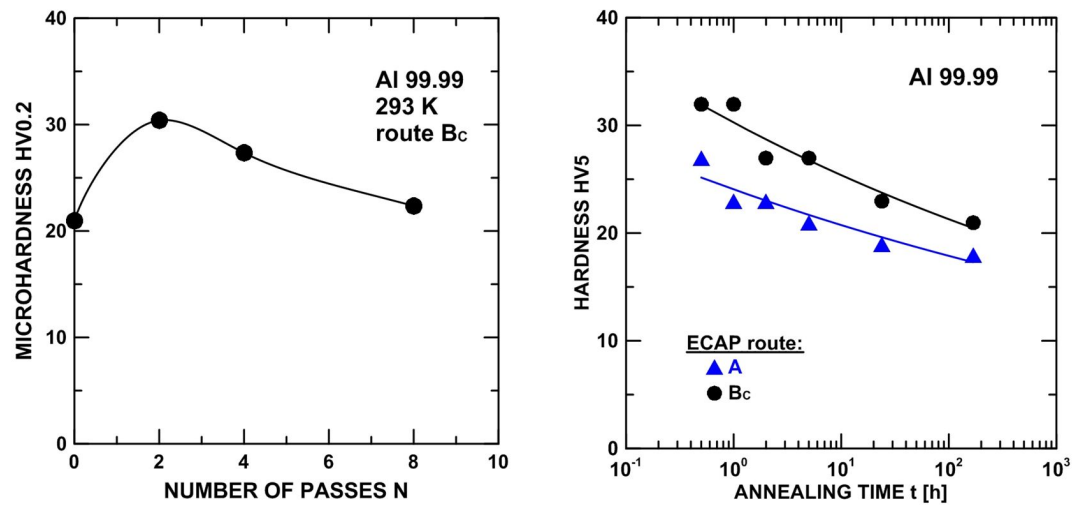

Figure 5. Hardness changes (a) with respect to number of ECAP passes, and (b) as a function of annealing time at 473 $\mathrm{K}$ for two different ECAP routes.

\subsubsection{Nanoporosity after ECAP processing}

It is generally recognized that the ECAP process could produce a submicrocrystalline bulk material with a relatively uniform structure and $100 \%$ density for a wide range of materials from pure metals, solid-solution alloys, commercial alloys, to metal matrix composites [1]. However, the previously performed analysis of the data on the influence of the number of passes of equal-channel angular pressing on the elastic-plastic properties and defect structure of pure aluminium demonstrated that these characteristics of mechanical properties are substantially affected by the evolution of the nanoporosity formed during equal-channel angular pressing [13-15]. Thus, to determine the total volume of nanoporosity which could be generated by ECAP, two selected samples of pure aluminium were pressed for a total of one (specimen A1) and four (specimen A4) ECAP passes, 
respectively, and for comparison reasons some part of these specimens were underwent by subsequent pressurization treatment by high hydrostatic pressure [16]. The samples were investigated by small-angle X-ray scattering (SAXS) and dilatometry [13].

Some differences were found in the fractional volume of the nanopores $\Delta \mathrm{V} / \mathrm{V}$ when compared specimen A1 to specimen A4. The values $\Delta \mathrm{V} / \mathrm{V}_{\max }$ correspond to the as-pressed state of specimens (after ECAP only) and the values $\Delta \mathrm{V} / \mathrm{V}_{\text {min }}$ were evaluated for the state after ECAP and subsequent pressurization which represents a rejuvenative treatment for elimination of nanopores. The evaluated values are $\Delta \mathrm{V} / \mathrm{V}_{\max }=5 \times 10^{-3}$ and $\Delta \mathrm{V} / \mathrm{V}_{\min }=2.5 .10^{-3}$ for specimen $\mathrm{A} 1$ and $\Delta \mathrm{V} / \mathrm{V}_{\max }=7 \times 10^{-3}$ and $\Delta \mathrm{V} / \mathrm{V}_{\text {min }}=3 \times 10^{-3}$ for specimen $\mathrm{A} 4$, respectively. No substantial difference in the average size of the nanopores $(\sim 20-30 \mathrm{~nm})$ was found between the specimens investigated. The values $\Delta \mathrm{V} / \mathrm{V}$ determined by small-angle $\mathrm{X}$-ray scattering and dilatometry were about the same; e.g. the fractional volume $\Delta \mathrm{V} / \mathrm{V}_{\min }=3 \times 10^{-3}$ by (SAXS) of specimen A4 agreed very well with $\Delta \mathrm{V} / \mathrm{V}_{\min }=2.5 \times 10^{-3}$ as determined by dilatometry. On the basis of the aforementioned results we can conclude that ECAP deformation achieves strongly enhanced concentration of vacancy agglomerates type defects. The effect of the spectrum of the point defects and the internal stresses on elasticity and anelasticity of ECAPed aluminium has been reported elsewhere [17].

In recent years using a back-pressure ECAP facilities [4] has become an area of special interest. An important advantage in imposing a back-pressure may be a decrease of nanoporosity in the pressed material [18]. However, additional experiments are needed to evaluate the role of a back-pressure in elimination of nanoporosity.

\section{Microstructural features of ultrafine-grained materials}

Ultrafine-grained (UFG) materials processed by ECAP differ qualitatively and quantitatively from their coarse-grained (CG) counterparts in terms of their characteristic structural parameters and thus their creep behaviour cannot be easily compared with that documented for CG materials. It is important to note in this respect that UFG materials are characterized by great extension of internal interfaces; therefore, grain boundary diffusion processes have to be involved in the formation of their structure-sensitive properties, especially at elevated temperature [19].

The characteristics of the microstructures introduced by ECAP have been evaluated in numerous investigations [4]. However, most of these earlier investigations employed transmission electron microscopy (TEM) for determinations of the grain sizes produced by ECAP and the nature of any dislocation interactions occurring within grains. The application of modern imaging methods to the examination of microstructures in UFG materials processed by ECAP has permitted a more detailed investigation of a possible link between internal microstructures of UFG metals and alloys and their mechanical and/or creep behaviour [4]. Diffraction-based techniques for localized crystal orientation measurements, such as electron backscatter diffraction (EBSD), are of central importance today for characterizing finescale microstructural features [20-23]. 
The new experimental technique of EBSD considerably extended the possibilities of metallography to estimate reliably the quantitative structural characteristics of materials [23]. It enables the numerical classification of boundaries separating the regions of different orientations of their lattice structure. The magnitude of the mutual misorientation can be continuously selected and thus the regions with a misorientation less than a prescribed value as well as their boundaries can be recognized. There is a vast literature devoted to the observation by EBSD and precisely defined misorientation of boundaries and the conventional grain boundary classification based on suitably polished and etched planar surfaces as observed by optical microscopy or by boundaries observed by electron microscopy and EBSD (see e.g. [24]). As can be expected, the EBSD method is more reproducible, independent of detailed etching conditions etc., and the surface area intensities are usually higher (equivalently, the mean random profile chord is smaller). In this section a division of boundaries into true subboundaries with misorientations $\Delta<10^{\circ}$, transitional subboundaries with $10^{\circ} \leq \Delta<15^{\circ}$ and high-angle grain boundaries with $\Delta \geq 15^{\circ}$ was made.

Such an approach is of primary importance in the examination of materials produced by severe plastic deformation (SPD), without change of shape, producing materials with ultrafine grains (e.g. [3,5]) and considerably different properties in comparison with CG materials. The reason for this difference is to a certain degree purely geometric and consists in different grain and subgrain boundary structures, which play an important role in mechanical, thermal and other properties.

This section describes the results of structural examinations of high purity aluminium and its selected precipitation-strengthened alloys processed by ECAP. The microstructure was revealed by TEM, SEM and EBSD and analyzed quantitatively by stereological methods. The various factors influencing the as-pressed microstructures including the total strain imposed in ECAP processing, the processing routes and the nature of materials are examined in detail.

\subsection{Experimental materials and their microstructure after ECAP}

\subsubsection{Pure aluminium}

The aluminium used in this investigation was an extremely coarse-grained (grain size $\sim 5$ $\mathrm{mm}$ ) high purity (99.99\%) Al supplied in the form of rods. The rods were cut into short billets having a length of $\sim 60 \mathrm{~mm}$ and a cross-section $10 \mathrm{~mm} \times 10 \mathrm{~mm}$. ECAP was conducted at room temperature using route $A, B_{C}$ and $C$. Full details on the processing have been described elsewhere [25-27].

TEM results have shown that one ECAP pass leads to a substantial reduction in the grain size ( $1.4 \mu \mathrm{m})$, and the microstructure consists of parallel bands of grains oriented in the shearing direction. The microstructure is very inhomogeneous and the grain size varies from location to location. The inhomogeneous nature of the microstructure may reflect the coarse grain size $(\sim 5$ $\mathrm{mm}$ ) prior to ECAP. The grains subsequently evolve upon subsequent ECAP passes into a reasonably equiaxed and homogeneous microstructure with an average grain size of $\sim 1 \mu \mathrm{m}$ regardless of the particular ECAP routes. The microstructure is essentially homogeneous after four ECAP passes, although a tendency for grain elongation in the direction of the shear direc- 
tion of the last pressing operation is retained. Figure 6 gives an example of the microstructure in the cross-section normal to the pressing direction after four subsequent ECAP passes performed in different routes. TEM micrographs in Figure 7 give an example of the microstructure in cross-section after four and eight subsequent ECAP passes by route $B_{c}$ and $C$, respectively. The EBSD grain maps in Figure 8 indicate little dependence of the grain boundary disorientation distribution on the ECAPed $\mathrm{Al}$ processed by route $\mathrm{B}_{\mathrm{c}}$.
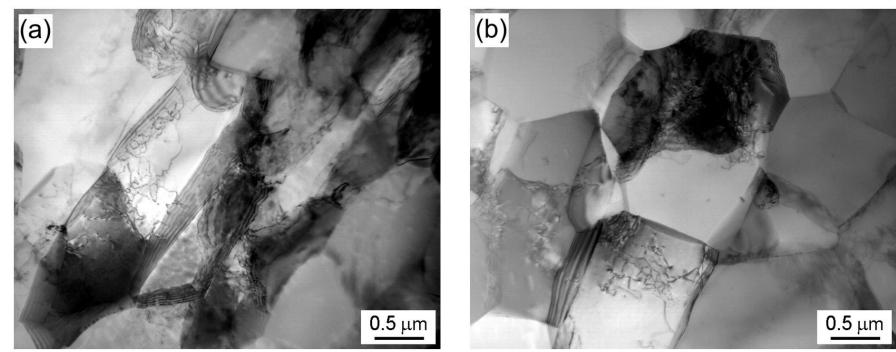

Figure 6. TEM micrographs of aluminium after four subsequent ECAP passes on route (a) A, and (b) B.
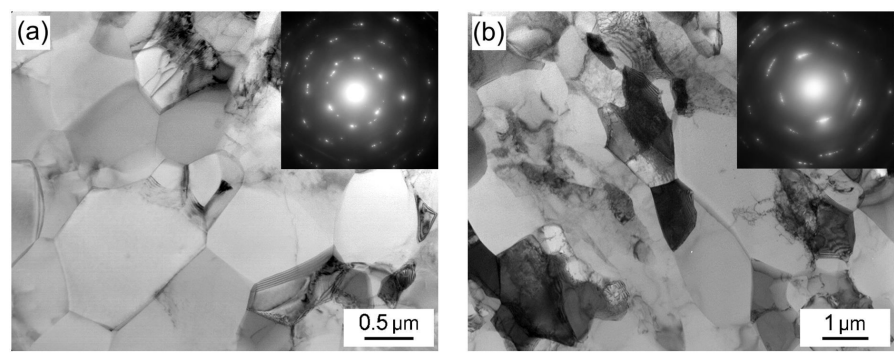

Figure 7. Typical microstructures and associated SAED patterns after passage through the die for (a) 4 pressings, route $B$ and (b) 8 pressings, route $C$.
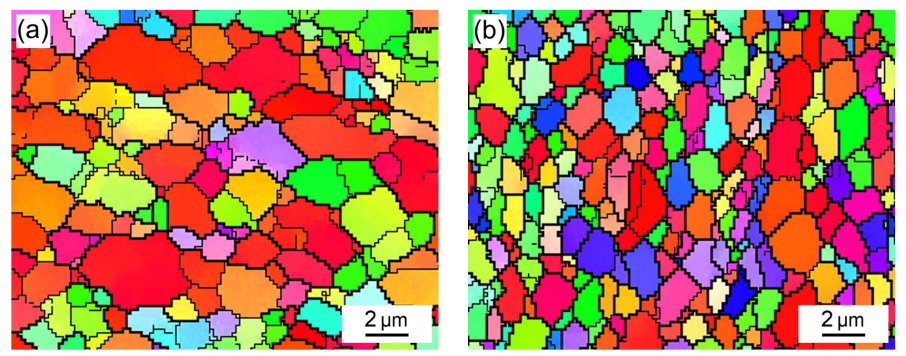

Figure 8. Grain maps for ECAPed Al after: (a) 4 passes, and (b) 8 passes by route B (EBSD). 
It can be expected that the creep behaviour of the ultrafine-grained pure aluminium will critically depend on the thermal stability of the microstructure. To explore the thermal stability of ECAP processed aluminium load-less annealing was conducted at temperature of $473 \mathrm{~K}$ for different periods of time (i.e. at the temperature of the intended creep tests). Microscopic examination revealed that the post-ECAP annealing makes the ECAP microstructure quite unstable and a noticeable grain growth occurs at the very beginning of annealing (Table 1). Simultaneously, annealing at $473 \mathrm{~K}$ gives measurable change in the Vickers microhardness.

\begin{tabular}{lcccc}
\hline Annealing & \multicolumn{2}{c}{ ECAP 4 passes route A } & \multicolumn{2}{c}{ ECAP 4 passes route B } \\
\cline { 2 - 5 } conditions & grain size $[\mu \mathrm{m}]$ & $\begin{array}{c}\text { microhardness } \\
\text { HV5 }\end{array}$ & grain size $[\mu \mathrm{m}]$ & $\begin{array}{c}\text { microhardness } \\
\text { HV5 }\end{array}$ \\
\hline no annealing & 0.9 & 37 & 0.9 & 38 \\
$473 \mathrm{~K} / 0.5 \mathrm{~h}$ & 6.6 & 27 & 4.5 & 32 \\
$473 \mathrm{~K} / 1 \mathrm{~h}$ & 7.9 & 23 & 4.8 & 32 \\
$473 \mathrm{~K} / 2 \mathrm{~h}$ & 7.3 & 23 & 4.8 & 27 \\
$473 \mathrm{~K} / 5 \mathrm{~h}$ & 7.3 & 21 & 5.3 & 27 \\
$473 \mathrm{~K} / 24 \mathrm{~h}$ & 12.2 & 19 & 5.0 & 23 \\
$473 \mathrm{~K} / 168 \mathrm{~h}$ & 13.4 & 18 & 10.4 & 21 \\
\hline
\end{tabular}

Table 1. Thermal stability and Vickers microhardness of the ECAP aluminium.

\subsubsection{Precipitation-strengthened aluminium alloys}

In evaluating the microstructure characteristics of ultrafine-grained materials processed by ECAP at elevated and high temperatures, it is very important to recognize that these ultrafinegrained microstructures are frequently unstable at these temperatures as it was just demonstrated by the above mentioned results of thermal instability of pressed pure aluminium. However, it is often feasible to retain an array of ultrafine grains even at very high temperatures by using materials containing second phases or arrays of precipitates. This was a reason why two precipitation-strengthened aluminium alloys were used in this investigation.

It has been shown that addition to aluminium alloys of even very small amounts of Sc (typically, 0.2wt.\%) strongly improves the microstructures of the alloys and their mechanical properties so that these alloys are suitable for use in engineering applications [28]. Scandium additions of $\sim 0.2 \mathrm{wt} . \% \mathrm{Sc}$ to pure aluminium are sufficient to more or less retain a small grain size at elevated temperatures [29]. Further, some reports have demonstrated that it is possible to achieve high ductilities in Al-Mg-Sc alloys by using ECAP to introduce an exceptionally small grain size [30]. The creep behaviour of conventional Al-Mg alloys is extensively described in the literature. The synergy of solid-solution strengthening and precipitate strengthening has, however, not been extensively studied at elevated and high temperatures [31]. Very little information is available at present on the creep properties of ultrafinegrained Al-Sc and Al-Mg-Sc alloys [32-38]. Accordingly, the present investigation was initiated to provide a more complex information on the creep behaviour of these aluminium alloys in their ultrafine-grained states. 
An Al-0.2wt.\%Sc alloy was produced by diluting an Al-2.0wt.\%Sc master alloy with $99.99 \mathrm{wt} . \%$ pure aluminium. The resulting ingots were subjected to a homogenization and grain-coarsening treatment at $893 \mathrm{~K}$ for 12 hours and then aged in air at $623 \mathrm{~K}$ for 1 hour. In the as-fabricated condition, the extremely coarse grain size was measured as $\sim 8 \mathrm{~mm}$. The ECAP was conducted at the Institute of Physics of Materials AS CR Brno, Czech Republic, using the same die and procedure as it was reported earlier for pure aluminium (i.e. up to a total 8 ECAP passes at room temperature). The details concerning an Al-0.2wt.\%Sc alloy have been reported elsewhere [33-35]. The ternary Al-Mg-Sc alloy was fabricated at the Department of Materials Science and Engineering, Faculty of Engineering, Kyushu University, Fukuoka, Japan. The alloy contained $3 \mathrm{wt} . \% \mathrm{Mg}$ and $0.2 \mathrm{wt} . \% \mathrm{Sc}$ and it was prepared from 99.99\% purity Al, $99.999 \%$ purity Sc and $99.9 \%$ purity $\mathrm{Mg}$. Full details on the fabrication procedure are given elsewhere [32] but, briefly, the alloy was cast, homogenized in air for $24 \mathrm{~h}$ at $753 \mathrm{~K}$ and solution treated for $1 \mathrm{~h}$ at $883 \mathrm{~K}$. In the as-fabricated condition, the grain size was about $200 \mu \mathrm{m}$. Again, the ECAP was conducted using a solid die that had $90^{\circ}$ angle between the die channels and each sample was pressed at room temperature repetitively for a total of eight passes by route $\mathrm{B}_{\mathrm{C}}$.
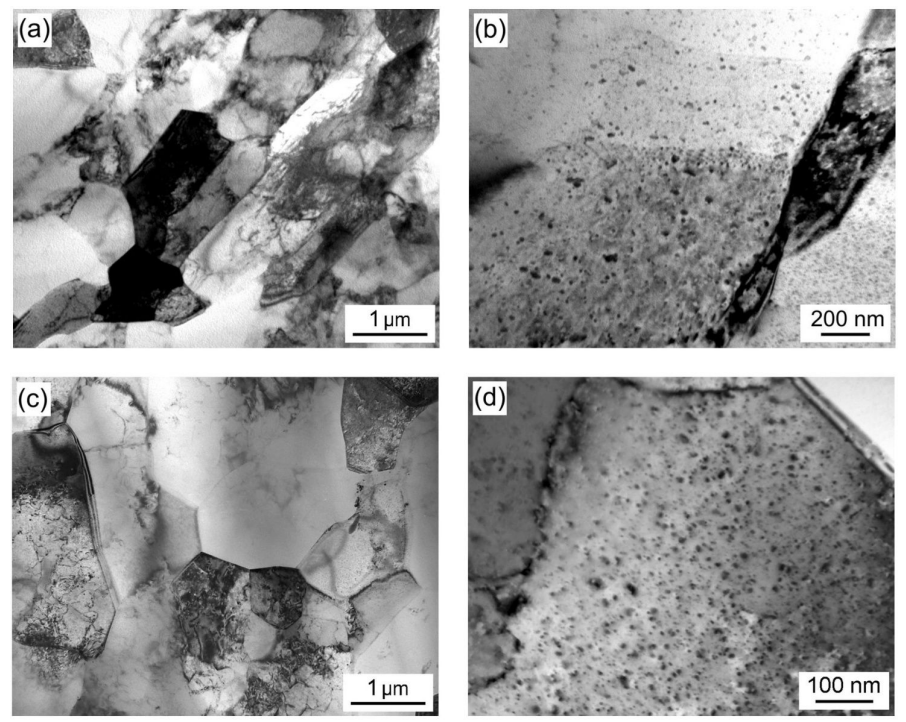

Figure 9. Microstructure in the Al-0.2wt.\%Sc alloy: (a) and (b) after ECAP ( $\mathrm{B}_{\mathrm{c}}, 8$ passes) and annealing for $1 \mathrm{~h}$ at $623 \mathrm{~K}$, (c) and (d) after creep at $473 \mathrm{~K}$.

Figures 9a,b and 10a,b show the microstructure of Al-0.2wt.\%Sc and Al-3wt.\%Mg-0.2wt.\%Sc alloys in their as-pressed states. Experiments on Al-0.2wt.\%Sc and Al-3wt.\%Mg-0.2wt.\%Sc alloys revealed that processing by ECAP reduced the grain size to $\sim 0.4 \mu \mathrm{m}$ and subsequent annealing at $623 \mathrm{~K}$ and $1 \mathrm{~h}$ and creep testing gave the grain sizes $\sim 0.9 \mu \mathrm{m}$ for an Al-0.2wt. $\%$ Sc alloy and $~ 1.5 \mu \mathrm{m}$ for an Al-3wt.\%Mg-0.2wt.\%Sc alloy, respectively. Figures 9c,d and 
10c, d give examples of the microstructure of the alloys in the longitudinal sections parallel to the pressing direction after creep exposures at $473 \mathrm{~K}$. As will be shown later on no substantial difference in the relative fractions of high-angle $\left(\theta>15^{\circ}\right)$ grain boundary population after ECAP was found between the alloys investigated. These fractions were slightly increased during creep exposure up to an average value $~ 70 \%$.
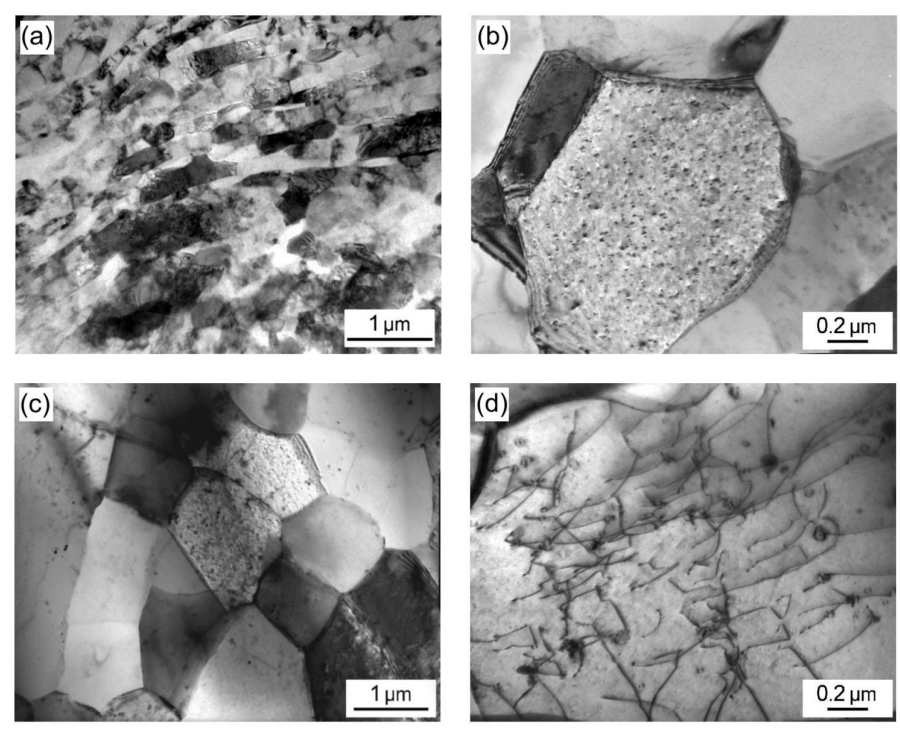

Figure 10. Microstructure in the Al-3wt.\%Mg-0.2wt.\%Sc alloy: (a) and (b) after ECAP ( $\mathrm{B}_{\mathrm{c}}, 8$ passes) and annealing for 1 h at $623 \mathrm{~K},(\mathrm{c})$ and (d) after creep at $473 \mathrm{~K}$.
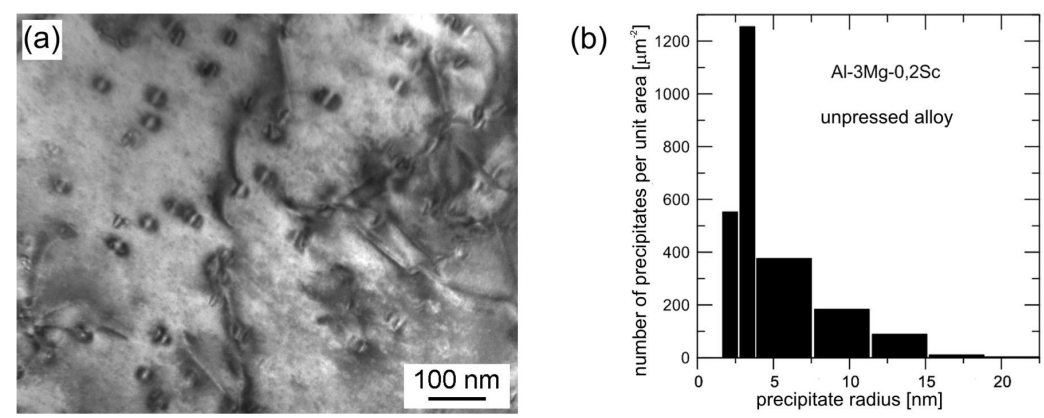

Figure 11. TEM micrograph showing the presence of coherent $\mathrm{Al}_{3} \mathrm{Sc}$ precipitates in unpressed sample, and (b) precipitate size distribution in unpressed sample.

Figures 9b,d and 10b,d exhibit TEM micrographs, which demonstrate the presence of coherent $\mathrm{Al}_{3} \mathrm{Sc}$ precipitates within the matrices of both alloys. $\mathrm{Al}_{3} \mathrm{Sc}$ precipitates are indicated by a 
coherency strain contrast [39]. A mean size of precipitates was $\sim 5 \mathrm{~nm}$ after creep testing of the Al-3wt.\%Mg-0.2wt.\%Sc alloy and a mean size of precipitates slightly large was recorded for the Al-0.2wt.\%Sc alloy ( $6 \mathrm{~nm}$ [35]). Figure 10d shows dislocation microstructure observed after creep exposure of ECAPed Al-3wt.\%Mg-0.2wt.\%Sc. The dislocation pairs present in both alloys containing the smallest precipitate radii are very frequent. For larger precipitates the dislocations are pinned efficiently by $\mathrm{Al}_{3} \mathrm{Sc}$ precipitates as climbing becomes slower. Figure 11a exhibits TEM micrograph of an Al-3wt.\%Mg-0.2 wt.\%Sc alloy showing the presence of coherent $\mathrm{Al}_{3} \mathrm{Sc}$ precipitates in an unpressed sample, and Figure $11 \mathrm{~b}$ presents precipitate size distribution in an unpressed alloy.

\subsection{Microstructure developed during creep}

\subsubsection{Pure aluminium}

It can be expected that the creep behaviour of the UFG material will be influenced critically upon the subsequent thermal stability of its microstructure. To explore this effect microscopic examination of grain size change in pure aluminium during creep exposure at $473 \mathrm{~K}$ and $15 \mathrm{MPa}$ were performed. It is important to note that each creep specimen was heated to the testing temperature in the furnace of the creep testing machine over a period of $\sim 2 \mathrm{~h}$ and then held at the testing temperature for further $\sim 2 \mathrm{~h}$ in order to reach thermal equilibrium. Consequently, the microstructure characteristics of the ECAP material at the onset of the creep testing were similar to that shown in Table 1. No substantial coarsening of grains has been observed during creep exposure at $473 \mathrm{~K}$ (see Table 2).

\begin{tabular}{llcc}
\hline Specimen & ECAP conditions & Grain size $[\mu \mathrm{m}]$ & Time to fracture $[\mathrm{h}]$ \\
\hline A4 & route A, 4 passes & 6.4 & 79 \\
\hline A8 & route A, 8 passes & 7.0 & 26 \\
\hline A12 & route A, 12 passes & 6.7 & 17 \\
\hline B4 & route B, 4 passes & 8.7 & 62 \\
\hline B8 & route B, 8 passes & 7.2 & 60 \\
\hline B12 & route B, 12 passes & 8.8 & 39 \\
\hline
\end{tabular}

Table 2. Grain size of the ECAP material after creep at $473 \mathrm{~K}$ and $15 \mathrm{MPa}$.

TEM observations were used also to established details of microstructure evolution during creep. The micrographs in Figure 12a,b illustrate a dislocation substructure inside the grains. The dislocation lines were wavy and occasionally tangled with each other. It is know that large grains in UFG materials contain dislocations while grains smaller than a certain size are dislocation free $[3,6]$. EBSD measurements were taken to determine the grain boundary misorientation and the value of relative fraction of a high-angle grain boundary $\left(\theta>15^{\circ}\right)$ population (for details see 3.3.2.). 

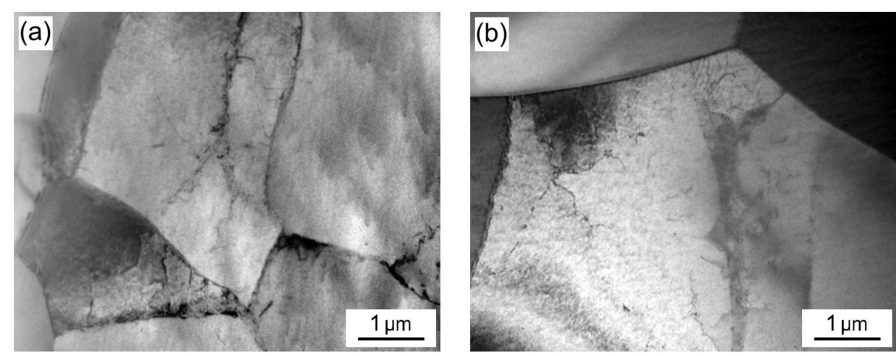

Figure 12. TEM micrographs from the longitudinal section of an aluminium processed by ECAP route $B_{c}(a)$ after 1 ECAP pass and creep, (b) after 8 ECAP passes and creep. Creep at $473 \mathrm{~K}$ and $15 \mathrm{MPa}$.

\subsubsection{Precipitation-strengthened alloys}

For comparison reasons, some results of microstructural changes in Al-0.2wt.\%Sc and Al-3wt. $\% \mathrm{Mg}-0.2 \mathrm{wt}$.\%Sc alloys during creep were presented earlier in 3.1.2. It was found that creep exposures of an Al-0.2wt.\%Sc alloy at $473 \mathrm{~K}$ and $20 \mathrm{MPa}$ caused the changes in (sub)grain sizes initially resulting from ECAP pressing. Figure 13a shows the microstructure after 8 ECAP passes and subsequent creep exposure. TEM analysis revealed that the average (sub)grain size increases from $\sim 0.4 \mathrm{um}$ to $\sim 1.3 \mu \mathrm{m}$ after creep exposure. The (sub)grain growth was effected by presence of coherent $\mathrm{Al}_{3} \mathrm{Sc}$ precipitates (Figure 13b) which to some extent pinned the boundaries against their migration and restricted the movement of dislocation.
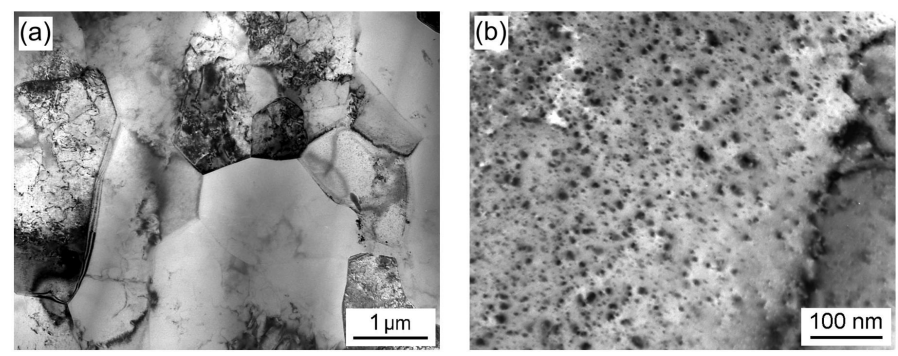

Figure 13. Microstructure of Al-0.2wt.\%Sc alloy after 8 ECAP passes and subsequent creep exposure at $473 \mathrm{~K}$ and 20 $\mathrm{MPa}$. (a) microstructure, and (b) precipitates $\mathrm{Al}_{3} \mathrm{Sc}$.

The EBSD data indicate that the number of high angle-boundaries $\left(\theta>15^{\circ}\right)$ measured in the specimens after ECAP and subsequent creep exposure is strongly dependent on the number of ECAP passes. The number of high-angle grain boundaries is increasing with increasing number of ECAP passes from approximately $2 \%$ in the specimen after 1 ECAP pass and subsequent creep to $\sim 70 \%$ in the specimen after 8 ECAP passes and subsequent creep. It was reported [4] that the grain boundary sliding can occur in UFG materials at elevated temperatures. Thus we can suppose that changes in the number of high-angle grain boundaries in 
the microstructure of ECAPed materials during creep tests can affect their creep behaviour by increasing the contribution of grain boundary sliding to the total creep strain [27].

The EBSD analyses were performed on the several places of the gauge length of creep specimen after ECAP and subsequent creep revealed scatter in the number of high angle grain boundaries (HAGBs). In the Figure 14 the minimal and maximal measured values of the number of HAGBs are plotted. The inspection of Figure 14 shows that the scatter in HAGBs can be particularly expected after creep tests in the specimens with lower number of ECAP passes. The heterogeneous distribution of HAGB can probably influence the homogeneity of grain boundary sliding. In the areas with the higher number of HAGBs the grain boundary sliding will be more intensive than in the surrounding areas [8].

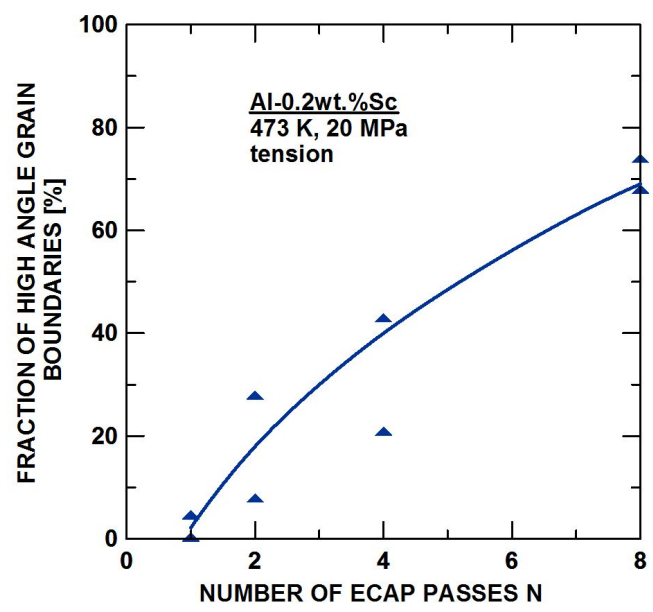

Figure 14. Fraction of high angle grain boundaries as a function of the number of ECAP passes in the Al-0.2wt.\%Sc alloy.

The investigation of the unetched surfaces of the specimens after 2-8 ECAP passes and after creep exposure revealed the appearance of mesoscopic shear bands [14,15,35, 40-42] lying near to the shear plane of the last ECAP pass (Figure 15). On the surface of specimens the mesoscopic shear bands were particularly observed near the fracture region and their frequency decreased rapidly with increasing distance from the fracture. On the specimen surface after 8 ECAP passes the mesoscopic shear bands already covered almost the whole gauge length. It was found that the width of the bands decreases with increasing number of ECAP passing and after 8 ECAP passes the average width of the bands was $\sim 35 \mu \mathrm{m}$ as it is shown in Figure 15. The analyses of microstructure on the interfaces of the bands found that in the vicinity of these interfaces high heterogeneity in the distribution of HAGBs can be observed (Figure 15). The formation of the mesoscopic shear band can be related to inhomogeneity of microstructure of ECAPed alloy after creep exposure. Examination by EBSD revealed that the microstructure of mesoscopic shear bands is created by high-angle grain boundaries (Figure 15 and 16). 


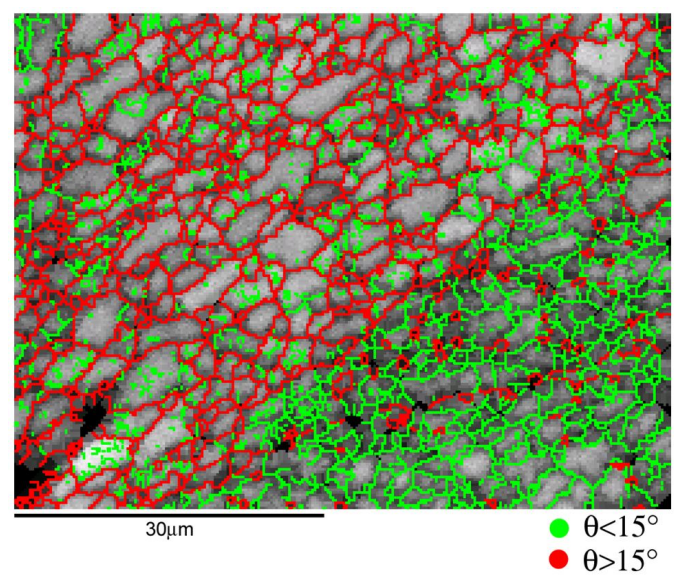

Figure 15. The heterogeneous distribution of HAGBs (red coloured) in the sample of an Al-0.2wt.\%Sc alloy after 4 ECAP passes and creep at $473 \mathrm{~K}$ and $20 \mathrm{MPa}$.

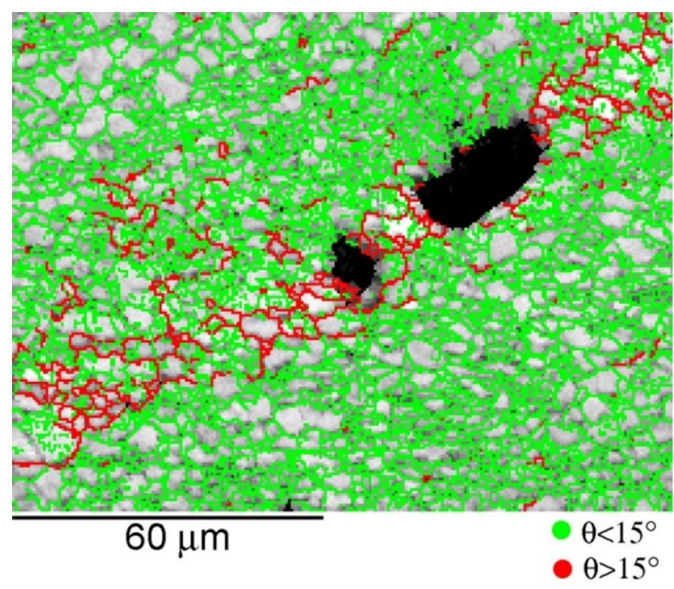

Figure 16. Appearance of the microstructure in the Al-0.2wt\%Sc alloy after 2 ECAP passes and subsequent creep at $473 \mathrm{~K}$. Tensile axis is horizontal, SEM.

\subsection{Unique features of microstructure in ultrafine-grained materials}

The processing technique used to obtain the UFG microstructure should strongly influence the creep properties of the material. This is primarily due to difference in microstructure as distribution of grains, subgrains, dislocation density and boundary character. The grain boundary character is usually quantified using the misorientation angle $\theta$ across grain boundaries, with high and low angle grain boundaries defined as $\theta \geq 15^{\circ}$ an $2^{\circ}<\theta<15^{\circ}$, 
respectively. Electron back scatter diffractions (EBSD) mapping has been used to quantitatively characterize boundaries in UFG materials [10,20,21,23,24]. Although the boundary spacing saturates after the first few ECAP passes, the fraction of high angle boundaries continues to increase with increasing ECAP passes [27,34,43]. In addition to grain size determination, there are a number of important microstructural parameters evaluated from EBSD but not available from conventional methods of grain characterization in particulars parameters relating to the grain orientations and boundary characters [44 - 46]. The following text describes representative results of quantitative characterization of UFG microstructure.

\subsubsection{Stereological estimates of UFG microstructure characteristics}

At each examined specimen there were made three mutually perpendicular planar metallographic sections denoted as $X Y, X Z$ (longitudinal sections) and $Y Z$ (transverse section), where $X, Y$ and $Z$ are the axes of the Cartesian coordinate system with $X$ along the last pressing direction and $\mathrm{Z}$ perpendicular to the bottom of the channel. The technique of automated EBSD in the scanning electron microscope was used for quantitative metallography. Four ranges of the boundary misorientation $\Delta$ were selected; $2^{\circ} \leq \Delta, 5^{\circ} \leq \Delta, 10^{\circ} \leq \Delta$ and $15^{\circ} \leq \Delta$. Then standard intercept counting [45] resulting in the mean number $\mathrm{N}_{\mathrm{L}}$ of profile chords per unit length of the examined test lines was carried out. In each specimen, six systematically selected directions of the test lines in each section were examined. The mean boundary areas unit volume were then estimated by the stereological relation $S_{V}=\left[2 N_{L}\right]$. Another important feature of the grain boundary structure is its inhomogeneity. The dispersion of grain profile areas can be qualified by the coefficient of variation $\mathrm{CV}_{\mathrm{a}}$ of the grain profile areas in a plane $\mathrm{CV}_{\mathrm{a}}=\frac{\sqrt{V}}{\bar{x}}$, where $\mathrm{V}$ is grain profile areas variation and $\bar{x}$ is the mean value of the grain profile area $[22,47,48]$. The coefficient of variation $\mathrm{CV}_{\mathrm{a}}$ of the profile areas is perhaps the best stereometric characteristic to evaluate homogeneity of microstructure and nowadays it is relatively easily attainable by a computer image analysis [49].

\subsubsection{Inhomogeneity of UFG microstructure}

There are numerous reports of the processing of various pure metals and metallic alloys by ECAP and many of these reports involve a detailed characterization of the microstructure. These results are summarized in recent reviews [3,4]. However, information seldom is reported on the percentage of high angle grain boundaries (HAGB's), an important parameter in the comparison of plasticity of different processing routes and materials [50]. It can be expected that samples with different distributions of misorientation across the grain boundaries will deform differently. Further, to provide information on the optimum microstructure of UFG materials we need to use an additional quantitative microstructural parameter other than just the average grain size critical for the creep behaviour and properties [51]. Such parameter could be a coefficient of profile $\mathrm{CV}_{\mathrm{a}}$ as a measure of homogeneity of materials microstructure [48].

Hence, the grain and subgrain structure of the creep specimens was revealed by means of EBSD and characterized by the coefficient of variation $\mathrm{CV}_{\mathrm{a}}$ of the profile areas. Four ranges of the boundary misorientation $\Delta$ between adjacent pixels were selected for examination using 
EBSD, which correspond namely to subboundaries, transitive and high angle grain boundaries within $2^{\circ} \leq \Delta$ and $5^{\circ} \leq \Delta$, transitive and high angle grain boundaries for $10^{\circ} \leq \Delta$, and mostly grains with HAGB's for $\Delta \geq 15^{\circ}$. Selected examples of images of $\mathrm{XZ}$ sections produced by EBSD of an Al-0.2wt.\%Sc are shown in Figure 17.
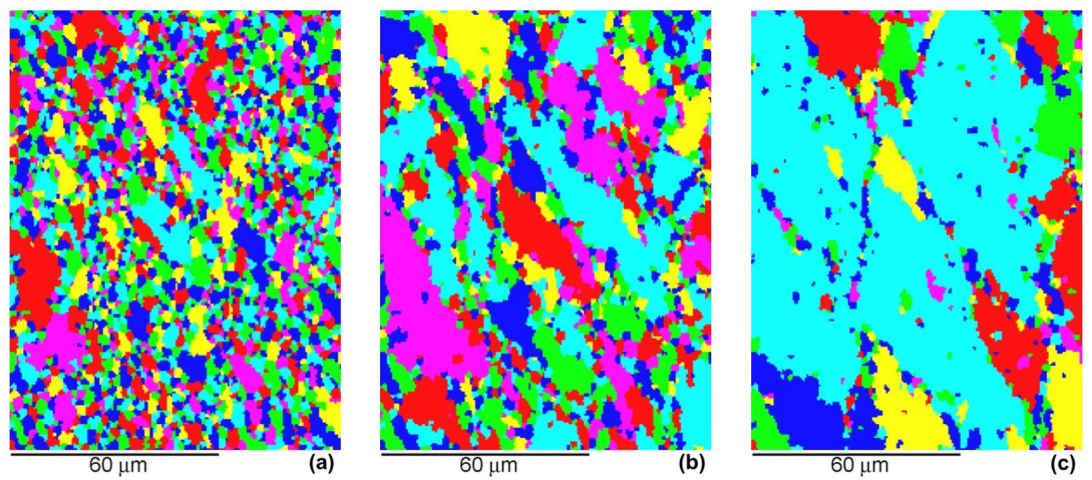

Figure 17. Selected examples of EBSD grain maps of an Al-0.2wt.\%Sc alloys after ECAP constructed for different grain misorientations: (a) subboundaries $\Delta \geq 2^{\circ}$, (b) transitive subboundaries and high angle boundaries $\Delta \geq 10^{\circ}$, and, (c) high-angle grain boundaries $\Delta \geq 15^{\circ}$.

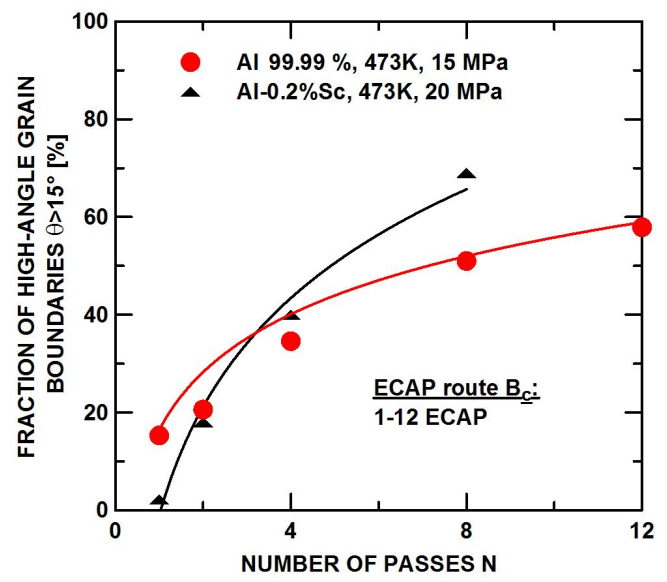

Figure 18. The fraction of high-angle grain boundaries in the crept samples as a function of the number of ECAP passes.

It was generally observed that with the increasing number of ECAP passes $\mathrm{N}$, a considerable amount of subgrain boundaries was gradually transformed to HAGB's as shown in Figure 18. At the same time, the local homogeneity of structure as characterized by the values of $\mathrm{CV}_{\mathrm{a}}$ with the increasing number $\mathrm{N}$ is gradually improved as demonstrates by Figure 19. Fig- 
ure 19 also shows the microscopic appearance of the specimens of an Al-0.2wt.\%Sc alloy crept under the same loading conditions $(473 \mathrm{~K}, 20 \mathrm{MPa})$ but processed by different numbers of ECAP passes $\mathrm{N}$. The values of $\mathrm{CV}_{\mathrm{a}}$ as high as 10 at $\mathrm{N}=2,1 \leq \mathrm{CV}_{\mathrm{a}}<2$ at $\mathrm{N}=4$, and 0.55 $\leq \mathrm{CV}_{\mathrm{a}} \leq 1$ at $\mathrm{N}=8$ were found. Extremely high value $\mathrm{CV}_{\mathrm{a}}$ at $\mathrm{N}=2$ demonstrates very high inhomogeneity of a mixture of subgrain and grain structures. The value of $\mathrm{CV}_{\mathrm{a}}$ in very homogeneous grain systems should not exceed the value of 1 [23]. It should be noted that extremely high values of the coefficient of variation $\mathrm{CV}_{\mathrm{a}}$ is a natural consequence of the short as well as long-range inhomogeneity of microstructure.

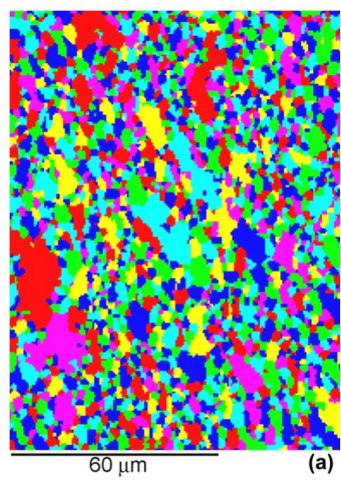

(a)

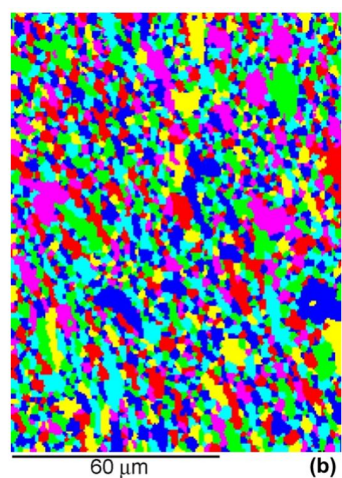

(b)

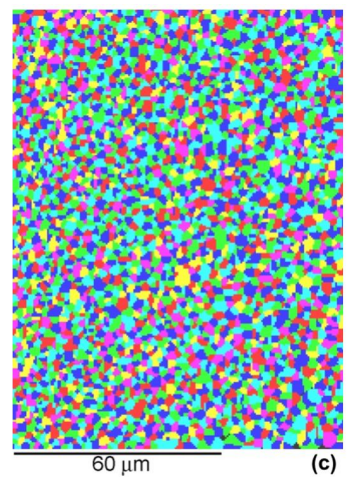

(c)

Figure 19. Grain maps of an Al-0.2wt.\%Sc alloy processed by different number $\mathrm{N}$ of ECAP passes and crept at $473 \mathrm{~K}$ and $20 \mathrm{MPa}$, and corresponding parameter $\mathrm{CV}_{\mathrm{a}}$ : (a) 2 passes, $\mathrm{CV}_{\mathrm{a}}>>2$, (b) 4 passes, $C \mathrm{~V}_{\mathrm{a}}<2$ and, (c) 8 passes, $0.55 \leq \mathrm{CV}_{\mathrm{a}}<1$.

The substantial grain coarsening especially in the case of pure metals came up during the creep exposures depending on stress and temperature thus manifesting the thermal instability of ultrafine-grained microstructure $[4,52,53]$. It is clear that in pure aluminium the grains grow rapidly at elevated temperatures because there are no precipitates within the crystalline lattice to restrict the movement of the grain boundaries by a "pinning effect". By contrast, submicrometer grains may be retained to relatively high temperatures in materials containing a distribution of fine precipitates as in the case of an Al-0.2\%Sc alloys containing $\mathrm{Al}_{3} \mathrm{Sc}$ precipitates [29]. The quantitative characterization of the inhomogeneity of the boundary structure is shown in Figure 20. It should be stressed that the values of the coefficient of profile area $\mathrm{CV}_{\mathrm{a}}$ as a measure of structure homogeneity strongly depend on the chosen ranges of misorientation $\Delta$ in EBSD analysis. Whereas the fraction of the subboundaries (low-angle grain boundaries) are dominating for $\Delta \geq 2^{\circ}$ (Figure 21a), the fractions of highangle grain boundaries $\left(\theta \geq 15^{\circ}\right)$ confirm their high share for the range of $\Delta \geq 15^{\circ}$ (Figure 21b). Detailed inspection of Figure 20b shows a strong dependence of $\mathrm{CV}_{\mathrm{a}}$ after creep on the number of ECAP passes. Substantial decrease of the values $\mathrm{CV}_{\mathrm{a}} 2^{\circ}$ for the precipitationstrengthened Al-0.2Sc alloy with increasing number of passes $\mathrm{N}$ for $\Delta \geq 2^{\circ}$ may be connected with the more rapid evolution boundaries having misorientation angles $\theta>15^{\circ}$ (Figure 20a). 

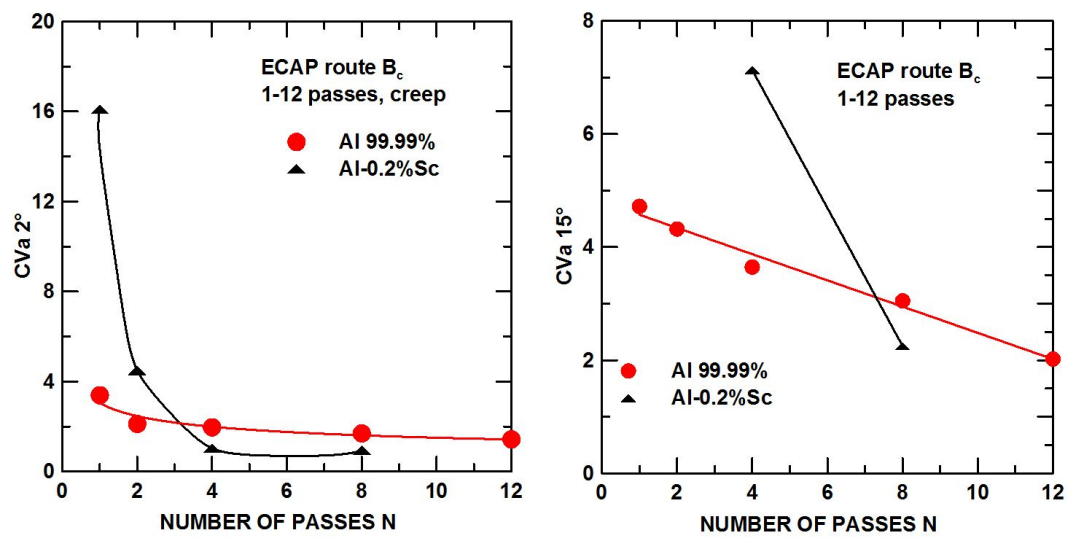

Figure 20. Coefficient of profile area CVa as a measure of homogeneity: $0.55 \leq \mathrm{CVa}<1$ (homogeneous system), and CVa $>2$ (multimodal grain size distribution). The chosen ranges of misorientation $\Delta$ in EBSD analysis: (a) $\Delta \geq 2^{\circ}$, (b) $\Delta \geq 15^{\circ}$.
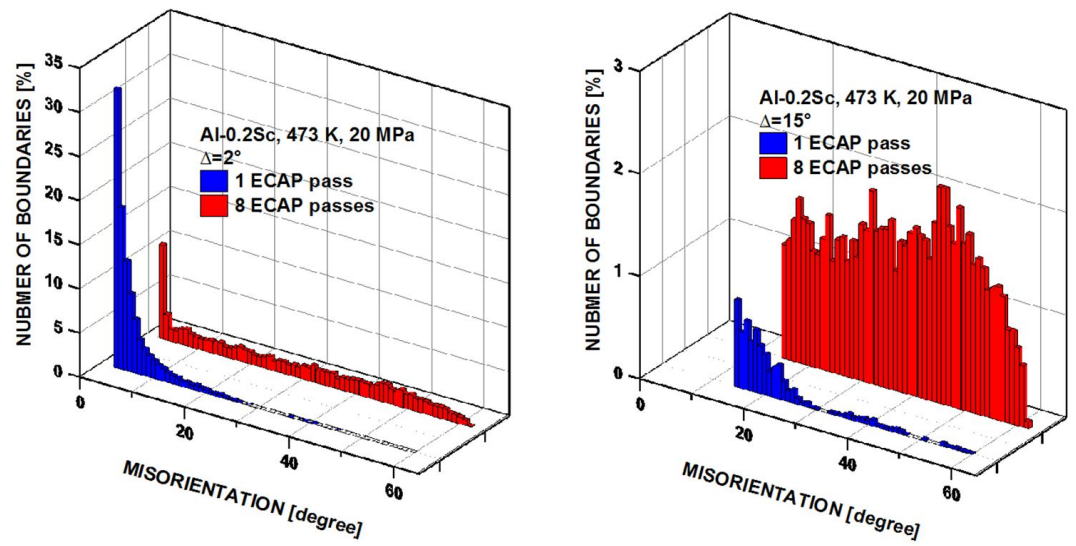

Figure 21. Distribution of boundaries with different misorientation $\theta$ for an Al-0.2wt.\%Sc alloy analysed in Figure 8 : (a) EBSD analysis for $\Delta \geq 2^{\circ}$, (b) $\Delta \geq 15^{\circ}$.

\section{Creep behaviour of UFG aluminium and its alloys}

The mechanical properties of bulk ultrafine-grained (UFG) materials at elevated and/or high temperatures are a new and important area of research [4]. However, there have been only a few investigations on the creep behaviour of bulk UFG materials processed by equal-channel angular pressing (ECAP) [43,54]. By comparison with the unpressed (coarse-grained) state, processing by ECAP may lead to considerable changes in the creep properties in bulk 
UFG materials including a decrease and/or an increase [8] in the minimum creep rate and the creep life. It is important to note that these trends may be noticeably dependent on the number of ECAP passes. Many investigations concerned with the identification of creep mechanisms have been undertaking using coarse-grained pure aluminium [55] and commercial aluminium alloys [56]. However, it is logical to expect that the mechanism of hardening/softening observed in the aluminium processed by ECAP may be different from that observed in the coarse-grained material. Consequently, it cannot be excluded that creep in the ECAP aluminium and its alloys is controlled by different creep mechanism(s) than that in the coarse material. Thus, neither phenomenological nor microscopic aspects of the creep behaviour of materials processed by ECAP have been understand sufficiently as yet.

This section reports a series of creep experiments that were conducted on specimens of pure aluminium and its $\mathrm{Al}-0.2 \mathrm{wt} . \% \mathrm{Sc}$ and $\mathrm{Al}-2 \mathrm{wt} . \% \mathrm{Mg}-0.2 \mathrm{wt} . \% \mathrm{Sc}$ alloys processed by equalchannel angular pressing. For comparison purposes, some creep tests were performed also on the unpressed materials. Creep tests were performed both in tension and compression.

\subsection{Effect of processing route on creep behaviour}

As discussed in more detail in Section 2.2. four distinct pressing routes have been identified (Figure 3). The ECAP processing was conducted by one or repetitive passes following either route $A, B$ (route $B_{C}$ was used only) or $C$. Figure 22 contains a complete record of the main creep parameters for the ECAP specimens of $\mathrm{Al}$ after creep testing in tension at $473 \mathrm{~K}$ and 15 $\mathrm{MPa}$ (each point represents the average results of two to three individual creep tests at the same loading conditions). Inspection of Figure 22 shows there are not very significant differences in creep properties of specimens prepared by the various ECAP processing routes. All three processing routes produce a significant increase in the minimum creep rate through the first four passes and a slight increase during subsequent pressing (Figure 22a). By contrast, the time to fracture (creep life) dramatically drops through four passes and then there is no significant differences among the number of following passes - Figure $22 \mathrm{~b}$.

Recently, attention has been given to effectiveness of the various ECAP routes in producing grain refinement in aluminium [10]. It has been demonstrated that ECAP is capable of producing refined structures with large fractions of high-angle boundaries [10] although the mechanisms involved in the formation of fine grains and high-angle boundaries in the deformation microstructure remain to be clarified. In this work microstructural investigation all routes examined indicated little differences in the grain size produced via the various ECAP routes. With increasing number of ECAP passes this difference decreases. Further, there was little apparent dependence of the misorientation on the various process route for an ECAP die having an internal angle equals to $90^{\circ}$. The misorientation data confirmed that repetitive pressing results in a progressive increase in the fraction of high-angle grain boundaries (Figure 18).

In related work, Sklenicka et al. $[11,57]$ carried out an extensive creep testing on pure aluminium processed by various ECAP routes. It was found that processing route had a little apparent effect on the creep behaviour of a pressed aluminium. However, the effect of grain growth during creep may tend to obscure the effect of different processing routes and the 
creep experiments are probably not a sufficiently refined procedure for picking up these rather small differences in the creep behaviour.
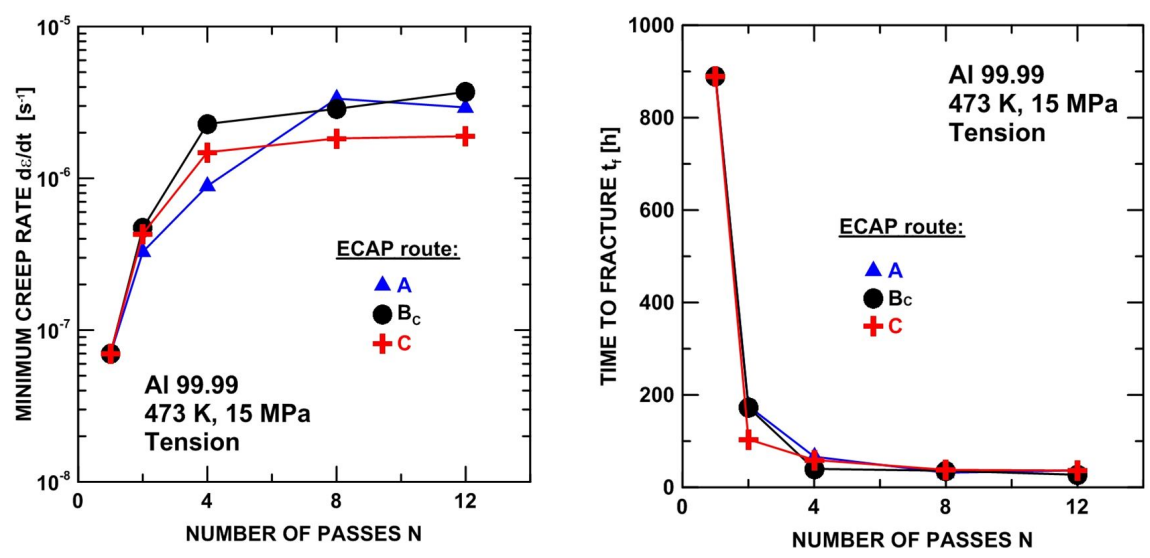

Figure 22. Influence of different ECAP routes and different number of ECAP passes on (a) creep rate, and (b) time to fracture.

\subsection{Creep behaviour of pure aluminium}

Creep tests were performed on the as-pressed specimens both in tension and compression in the temperature interval from 423 to $523 \mathrm{~K}$ under an applied stress range between 10 and 25 $\mathrm{MPa}$. The subsequent ECAP passes were performed by route $\mathrm{B}_{\mathrm{C}}$ (see part 2.2.) up to 12 passes.

\subsubsection{Creep behaviour}

Representative creep curves are shown in Figures 23 and 24. All of these plots were obtained at temperature of $473 \mathrm{~K}\left(\sim 0.5 \mathrm{~T}_{\mathrm{m}}\right)$ under an initial applied uniaxial tensile or compression stress of $15 \mathrm{MPa}$. The creep tests in tension were run up to the final fracture of the creep specimens, whereas the creep tests in compression were interrupted at a true strain of about $\sim 0.35$.

Standard $\varepsilon$ vs t creep curves in Figures 23a and 24a can be easily replotted in the form of the instantaneous strain rate $\mathrm{d} \varepsilon / \mathrm{dt}$ versus strain as shown in Figures $23 \mathrm{~b}$ and $24 \mathrm{~b}$. As demonstrated by figures, significant differences were found in the creep behaviour of the ECAP material when compared to its coarse-grained counterpart. First, the ECAP materials exhibits markedly longer creep life (Figure 23a) or markedly longer duration of creep exposure to obtain a strain of $\sim 0.35$ (Figure $24 \mathrm{~b}$ ) than coarse grained aluminium. Second, the minimum creep rate for the ECAP material is about one to two orders of magnitude less than that of coarse-grained material. Third, the shapes of tensile creep curves for the ECAP material after high number of pressing differ considerably from the tests conducted at small number of the ECAP passes by the extent of individual stages of creep. 

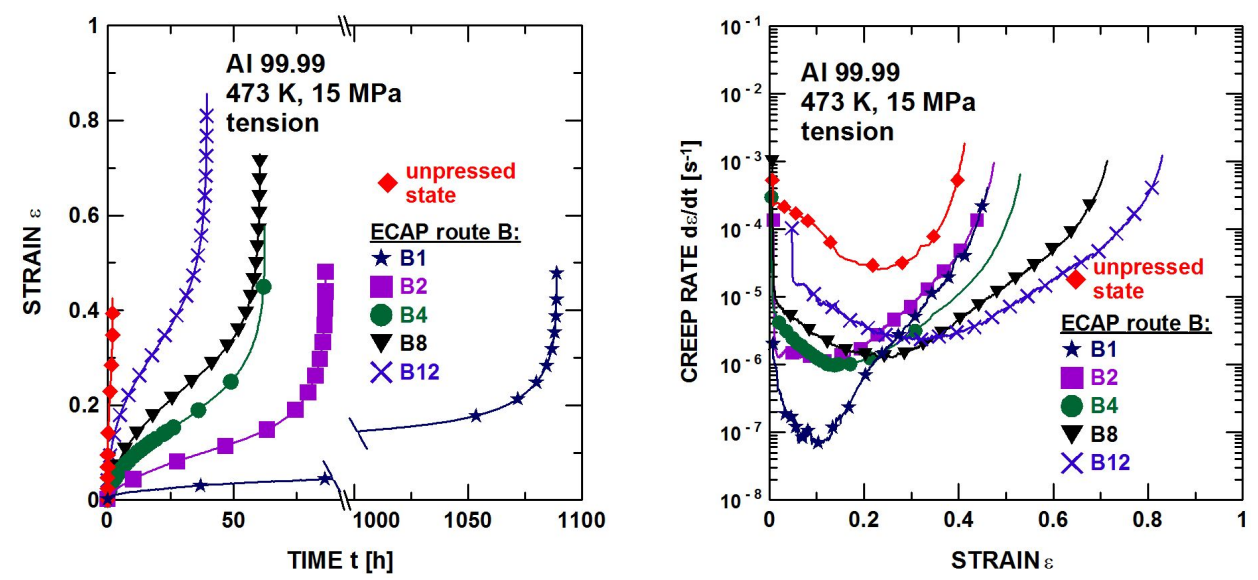

Figure 23. Standard creep and creep rate versus strain curves for unpressed state and various number of ECAP passes via route $B_{c}$ (creep in tension up to fracture).
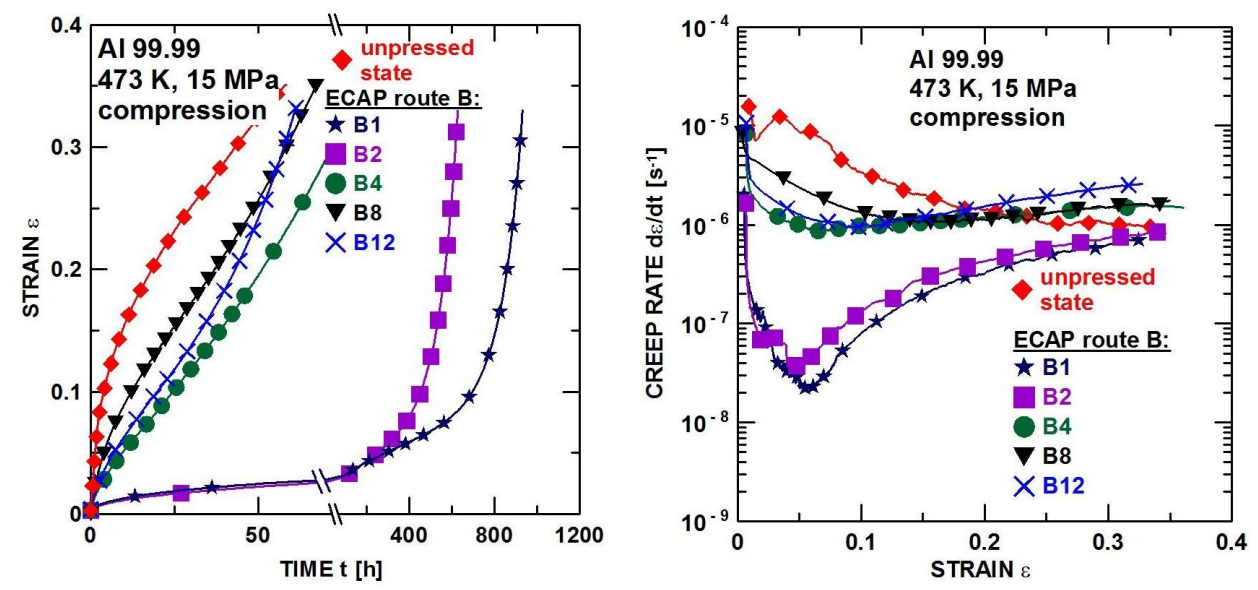

Figure 24. Standard creep and creep rate versus strain curves for unpressed state and various number ECAP passes via route $B_{c}$ (creep in compression up to strain $\sim 0.35$ ).

The difference in the minimum creep rate for the ECAP material and unpressed state consistently decreases with increasing number of ECAP passes (Figures $23 \mathrm{~b}$ and $24 \mathrm{~b}$ ). An additional difference is illustrated by Figure 25a, which shows the variation of the minimum creep rate with the applied stress for the ECAP specimens after 8 passes. The results demonstrate that at high stresses the minimum compressive creep rate of the ECAP material may be up to one order of magnitude lower than that of the unpressed material, although this difference decreases with decreasing applied stress and becomes negligible at $10 \mathrm{MPa}$. The 
observed values of the stress exponent $\mathrm{n}=(\partial \ln \dot{\varepsilon} / \partial \ln \sigma)_{T}$ are $\sim 6.6$ for the unpressed material, $\sim 4.8$ (creep in compression) and $~ 5.7$ (creep in tension) for the ECAP Al, respectively.

To determine the apparent activation energy for creep $Q_{c}$, the minimum creep rate was measured in the temperature interval from 423 to $523 \mathrm{~K}$ and at two tensile applied stresses 15 and $20 \mathrm{MPa}$, respectively. The activation energy for creep $Q_{c}$ is defined as

$$
Q_{c}=\left[\frac{\partial \ln \dot{\varepsilon}_{\min }}{\partial(-1 / k T)}\right]_{\sigma}
$$

Thus, the activation energy $Q_{C}$ can be derived from the slope of log $d \varepsilon / d t$ versus $1 / T$ plots shown in Figure 25b. A value of the apparent activation energy, $Q_{C}$, was determined by the least square methods. The $Q_{C}$ is stress dependent and equals to $129.7 \pm 16$ and $110.9 \pm 9$ $\mathrm{kJ} / \mathrm{mol}$ for stresses 20 and $15 \mathrm{MPa}$, respectively.
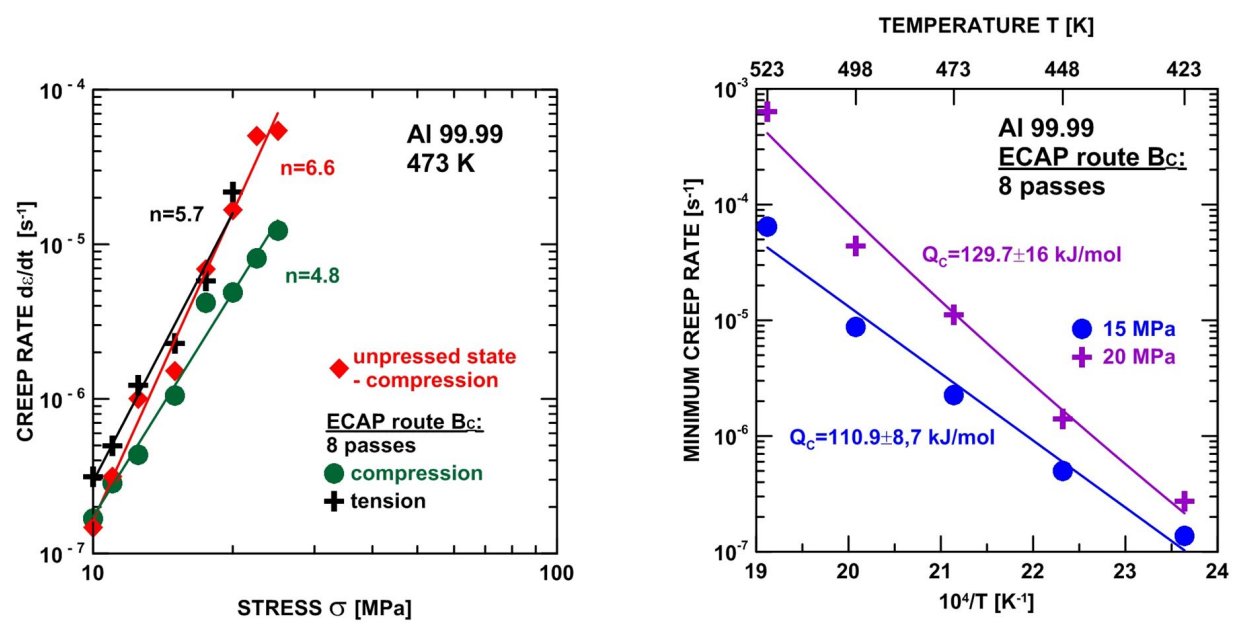

Figure 25. Dependence of minimum creep rate for unpressed state and 8 ECAP passes on: (a) applied stress, (b) testing temperature at two levels of stress.

\subsubsection{Grain boundary sliding (GBS)}

The total creep strain $\varepsilon$ generally consists of following contributions: the strains caused by dislocation glide and nonconservative motion of dislocations, grain boundary sliding (GBS) [58-60], stress directed diffusion of vacancies and by intergranular void nucleation and growth, respectively. However, it should be noted that not all of the above processes operating are independent of each other, as frequently assumed. A possible explanation for the occurrence of intensive GBS in UFG materials is that diffusion is more rapid in ECAP processed materials with highly non-equilibrium grain boundaries [4, 19, 61,62]. Accordingly, it appears that GBS is easier in these UFG materials. 
The amount of grain boundary sliding (GBS) was determined by measuring the surface offsets produced at the intersections of grain boundaries with marker lines transverse to the stress axis $[27,58]$. Figure 26 shows one clear example of the occurrence of grain boundary sliding in creep of the ECAP aluminium. Longitudinal displacements of the marker lines, $u$, due to GBS, together with the fraction of boundaries, $\kappa_{S}$, with observable GBS, were measured using SEM.

Grain boundary sliding was measured on the surfaces of the tensile specimens crept up to a predetermined strain $\varepsilon \approx 0.15$. Scanning electron microscopy made it possible to detect GBS characterized by $\mathrm{u} \geq 0.1 \mu \mathrm{m}$. However, GBS was not observed at all grain boundaries; that is why the relative frequency of sliding boundaries $\kappa_{\mathrm{s}}$ was determined. Then the strain component $\varepsilon_{\mathrm{gb}}$ due to GBS is expressed as [27,58]:

$$
\varepsilon_{\mathrm{gb}}=(1+\varepsilon) \bar{u} \cdot \kappa_{\mathrm{s}} / \bar{L}
$$

where the mean grain size $\bar{L}$ was determined by the linear intercept method and the overall contribution of GBS to the total creep strain in the specimen, $\gamma$, was estimated as $\gamma=\varepsilon_{\mathrm{gb}} / \varepsilon$. The results of GBS measurements are summarized in Table 3. It is evident that the fraction of boundaries $\kappa_{\mathrm{s}}$ increases as the number of ECAP passes increases. This result supports the idea that GBS is connected with microstructural changes of grain boundaries [27]. It is to note that in the best case (12 passes) the contribution of GBS to creep strain is only $33 \%$.

\begin{tabular}{cccccc}
\hline No of Passes & $\overline{\mathrm{u}}[\boldsymbol{\mu \mathrm { m } ]}$ & $\mathbf{K}_{\mathbf{s}}$ & $\overline{\boldsymbol{L}}[\boldsymbol{\mu \mathrm { m } ]}$ & $\boldsymbol{\varepsilon}_{\mathrm{gb}} \cdot \mathbf{1 0 ^ { 2 }}$ & $\boldsymbol{\varepsilon}_{\mathrm{gb}} \mathbf{\boldsymbol { \varepsilon } . 1 0 ^ { 2 }}$ \\
\hline 1 & 0.51 & 0.80 & 14.9 & 3.15 & 21.0 \\
\hline 2 & 0.48 & 0.83 & 12.7 & 3.60 & 24.0 \\
\hline 4 & 0.55 & 0.93 & 12.2 & 4.80 & 32.0 \\
\hline 8 & 0.49 & 0.91 & 10.8 & 4.70 & 31.0 \\
\hline 12 & 0.52 & 0.92 & 11.0 & 5.00 & 33.0 \\
\hline
\end{tabular}

Table 3. Summary of GBS measurements $(\varepsilon \cong 0.15)$.

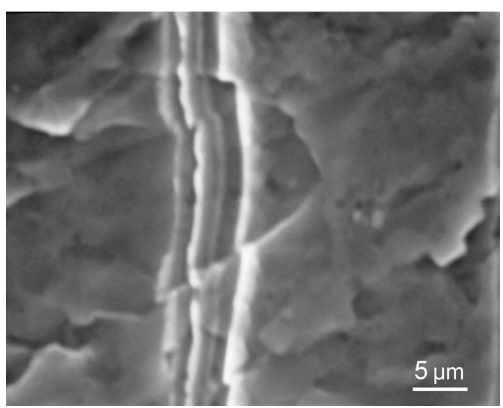

Figure 26. Example of grain boundary sliding in the ECAPed aluminium (route $B_{c}, 8$ passes) after creep testing at 473 $\mathrm{K}$ and $15 \mathrm{MPa}$. Tensile stress axis is horizontal. 


\subsubsection{Creep deformation mechanisms}

The mechanisms controlling the creep properties of pure metals have been usually identified from the dependence of the minimum and/or steady-state creep rate $\dot{\varepsilon}_{m}$ on stress $\sigma$, absolute temperature $\mathrm{T}$ and grain size $\mathrm{d}$, using a power-law expression of the form

$$
\dot{\varepsilon}_{m}=A \sigma^{n}(1 / d)^{p} \exp \left(-Q_{c} / R T\right)
$$

where $Q_{c}$ is the activation energy for creep. With this approach, the fact that $n, p$ and $Q_{c}$ are themselves functions of stress, temperature and grain size is conventionally explained by assuming that different mechanisms, each associated with different values of $n, p$ and $Q_{c}$, control the creep characteristics in different stress/temperature regimes. In turn, the dominant mechanisms under specific test conditions are then generally determined by comparing experimentally determined values of $n, p$ and $Q_{c}$ with the values predicted theoretically for different creep mechanisms.

In Figure 27, the minimum creep rates $\dot{\varepsilon}_{\text {min }}$ are plotted against applied stress $\sigma$ for pure aluminium using the data presented in Figure 25a. Experimental points are shown for both the unprocessed (coarse-grained) and for the UFG aluminium after 8 ECAP passes (only the results of tensile creep testing are used).

The broken lines in Figure 27 denote the model predictions of the theoretical creep rates according models for various creep deformation mechanisms, namely for superplastic flow, Nabarro-Herring $[59,63,64]$ and Coble $[59,65]$ diffusion creep and power-law creep by dislocation climb and glide processes. It should be stressed that the phenomenon of dislocation diffusion is not well understood on the fundamental level at present. The theoretical creep rates were calculated from equation (3) using the material data presented in Table 4.

\begin{tabular}{|c|c|c|c|c|c|c|c|c|}
\hline \multicolumn{9}{|c|}{$\mathrm{Al}(473 \mathrm{~K}) \mathrm{d}_{\mathrm{ECAP}}=1 \mu \mathrm{m} \mathrm{d}_{\mathrm{CREEP}}=12 \mu \mathrm{m}[27]$} \\
\hline $\begin{array}{l}\text { number of } \\
\text { curve }\end{array}$ & creep mechanism & $\mathrm{n}$ & $\mathbf{p}$ & A & $\begin{array}{l}\text { D } \\
{\left[\mathrm{m}^{2} \mathrm{~s}\right.}\end{array}$ & & $\begin{array}{l}\mathrm{Q} \\
{\left[\mathrm{kJ} \mathrm{mol}^{-1}\right]}\end{array}$ & source \\
\hline$(1),\left(1^{*}\right)$ & superplastic flow & 2 & 2 & 10 & $D_{G B}$ & $5.9 \times 10^{-14}$ & 86 & {$[66]$} \\
\hline$(2),\left(2^{\star}\right)$ & Nabarro - Herring creep & 1 & 2 & 28 & $D_{L}$ & $2.72 \times 10^{-20}$ & 143.4 & {$[66]$} \\
\hline$(3),\left(3^{\star}\right)$ & Coble creep & 1 & 3 & 62 & $D_{G B}$ & $5.9 \times 10^{-14}$ & 86 & {$[66][67]$} \\
\hline (4) & dislocation climb and glide & 5 & 0 & $10^{3}$ & $D^{*}$ & $1.9 \times 10^{-14}$ & 124 & {$[66]$} \\
\hline
\end{tabular}

Table 4. Creep mechanisms and material data.

It should be noted that grain growth occurs easily at the elevated temperatures used in creep experiments of pure metals. Indeed, the occurrence of significant grain growth in 
creep tests conducted on high-purity aluminium processed by ECAP at room temperature was observed $[27,36]$. Accordingly, two sets of the predicted theoretical rates were calculated in this analysis for both states of materials using the measured grain size after ECAP processing $\left(\mathrm{d}_{\text {ECAP }}\right)$ and after subsequent creep exposure $\left(\mathrm{d}_{\text {CREEP }}\right)$ [27]. The theoretical rates using $d_{\text {ECAP }}$ will be marked by simple number (e.g. 1 ) while a numbering with asterisk (e.g. $1^{*}$ ) will be used for the rates corresponding to $\mathrm{d}_{\text {CREEP }}$ in Figure 27.

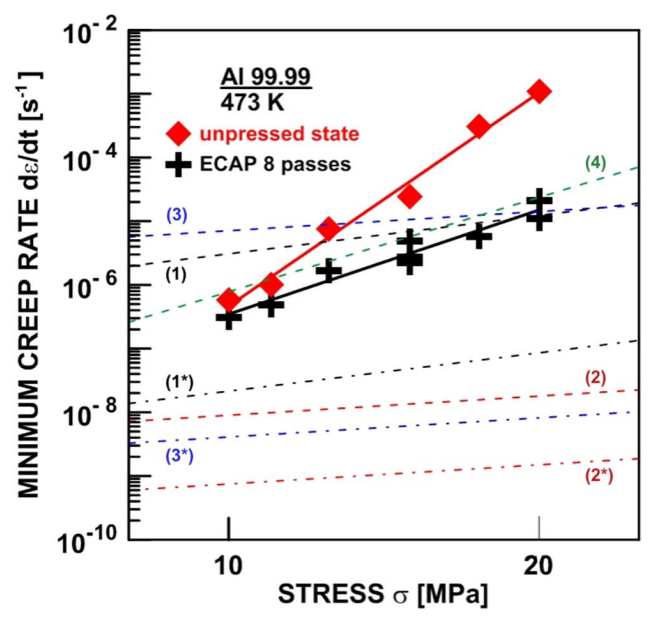

Figure 27. Experimentally determined and theoretically predicted the stress dependences of the minimum creep rates for various creep mechanisms in aluminium.

Figure 27 demonstrates that at high applied stresses the experimentally determined minimum creep rate of the ECAP aluminium may be up to two orders of magnitude lower than that of the unpressed material, although this difference decreases with decreasing applied stress and becomes nearly negligible at $10 \mathrm{MPa}$. The predictions show that under the creep loading conditions investigated Nabarro-Herring and Coble diffusion creep and superplastic flow are too slow to account for the creep deformation considering a significant grain growth in the pressed materials. Also shown in Figure 27 are the predicted theoretical creep rates for ultrafinegrained states $\left(\mathrm{d}_{\mathrm{ECAP}}\right)$ after ECAP which are within two to five orders of magnitude faster than that for the creep of coarsened materials. However, such predictions are not correct a priori due to thermal instability of microstructure of the pressed materials. Inspection of Figure 27 shows that for the pressed material there is an excellent agreement between the experimental datum points and the predicted creep behaviour based on dislocation climb and glide. Further, for $\mathrm{n} \geq 4$ creep is known to occur by diffusion-controlled movement of dislocations within grains and/or along grain boundaries (grain boundary sliding). The high value of $\mathrm{n}_{\mathrm{CG}}$ for the unpressed aluminium (Figure 27) could represent a regime leading into a power-law breakdown (PLB) region at rapid strain rates and/or high stress levels.

The analysis of Figure 27 indicates that creep in pure aluminium after ECAP occurs by the same mechanism as in conventional coarse-grained materials with intragranular dislocation 
glide and climb as the dominant rate-controlling flow process. Therefore, the activation energy for creep $Q_{C}$ should be the same as the value of the activation enthalpy of lattice selfdiffusion $\Delta \mathrm{H}_{\mathrm{SD}}\left(\Delta \mathrm{H}_{\mathrm{SD}} \cong 127-143 \mathrm{~kJ} / \mathrm{mol}\right.$ in aluminium [59]). The values obtained for $\mathrm{Q}_{\mathrm{C}}$ (Figure 25b) are somewhat lower than that of $\Delta \mathrm{H}_{\mathrm{SD}}$. Supposing that grain boundary sliding is controlled by grain boundary diffusion, which is assumed to be about 0.7 times that for lattice self-diffusion, the presented results give support to the assumption that GBS may be increasingly important in creep of the ECAP aluminium at low applied stresses.

It can be concluded that the creep resistance of high purity aluminium is increased considerably already after one ECAP pass. However, successive ECAP pressing leads to a noticeable decrease in the creep resistance. The results of microstructure investigations indicate that an inhomogeneity and thermal instability of the ECAP microstructure may strongly influence the creep behaviour of the pressed material [48].

\subsection{Creep behaviour of aluminium alloys}

The combination of solid-solution strengthening and precipitation strengthening in creep of aluminium alloys at elevated temperatures has not been extensively studied. Numerous reports dealt with the creep behaviour of Al-Mg solid solution [68-70]. Most precipitation strengthened aluminium alloys currently being used are limited to relatively low temperature usage, because of the dissolution and/or rapid coarsening of their precipitates. An exception represents $\mathrm{Al}-\mathrm{Sc}$ alloys containing low volume fractions of very fine coherent cuboidal $\mathrm{Al}_{3} \mathrm{Sc}$ precipitates. The dislocation creep behaviour of coarse-grained binary $\mathrm{Al}-\mathrm{Sc}$ alloys at $573 \mathrm{~K}$ and the precipitation strengthening effect of the $\mathrm{Al}_{3} \mathrm{Sc}$ phase were investigated by Fuller et al. [71] and Seidman et al. [72]. Recently, the effect of $\mathrm{Mg}$ addition on the creep behaviour of an Al-Sc alloy was reported by Marquis et al. [31]. It was found that the creep strength of an Al-3wt.\% Mg-0.2wt.\%Sc alloy, containing $\mathrm{Mg}$ in solid solution and $\mathrm{Al}_{3} \mathrm{Sc}$ as nanosize precipitates, is significantly improved compared to binary Al-Sc alloys.

\subsubsection{Creep behaviour}

As it was reported in Section 4.2. the processing by ECAP of a coarse-grained high purity aluminium provided a potential for marked improvement in the creep properties. Accordingly, Section 4.3. reports on a systematic study of the creep behaviour of the ECAP processed aluminium alloys containing low volume fraction of $\mathrm{Al}_{3} \mathrm{Sc}$ precipitates to elucidating the effect of ECAP on their creep resistance.

Figure 28a shows standard strain $\varepsilon$ versus time $t$ curves for the as-received (unpressed) Al-0.2wt.\%Sc and Al-3wt.\%Mg-0.2wt.\%Sc alloys and those for the same alloys processed by ECAP through 8 passes at $473 \mathrm{~K}$ and $50 \mathrm{MPa}$ (an exception is $80 \mathrm{MPa}$ for $\mathrm{Al}-3 w t . \% \mathrm{Mg}-0.2 \mathrm{wt}$. $\%$ Sc alloy in the as-received state). The creep tests in compression were interrupted at a true strain of about $\sim 0.35$. These standard creep curves were replotted in the form of the instantaneous creep rate $\mathrm{d} \varepsilon / \mathrm{dt}$ versus time $\mathrm{t}$ as shown in Figure $28 \mathrm{~b}$. It is clear that no-one of the creep curves exhibits a well-defined steady state. In fact this stage is reduced to an inflection point of the $\mathrm{d} \varepsilon / \mathrm{dt}$ versus $\mathrm{t}$ curve. Supposing that the instantaneous creep rate $\mathrm{d} \varepsilon / \mathrm{dt}$ at given 
stress and temperature is a certain measure of the "softness" of the microstructure, then the $\mathrm{d} \varepsilon / \mathrm{dt}-\mathrm{t}$ plots reveal the time evolution of this "softness". However, the $\mathrm{d} \varepsilon / \mathrm{dt}-\varepsilon$ plots may give additional information, since they reflect the effect of the plastic creep strain on the instantaneous "softness" of the microstructure (Figure 28c).
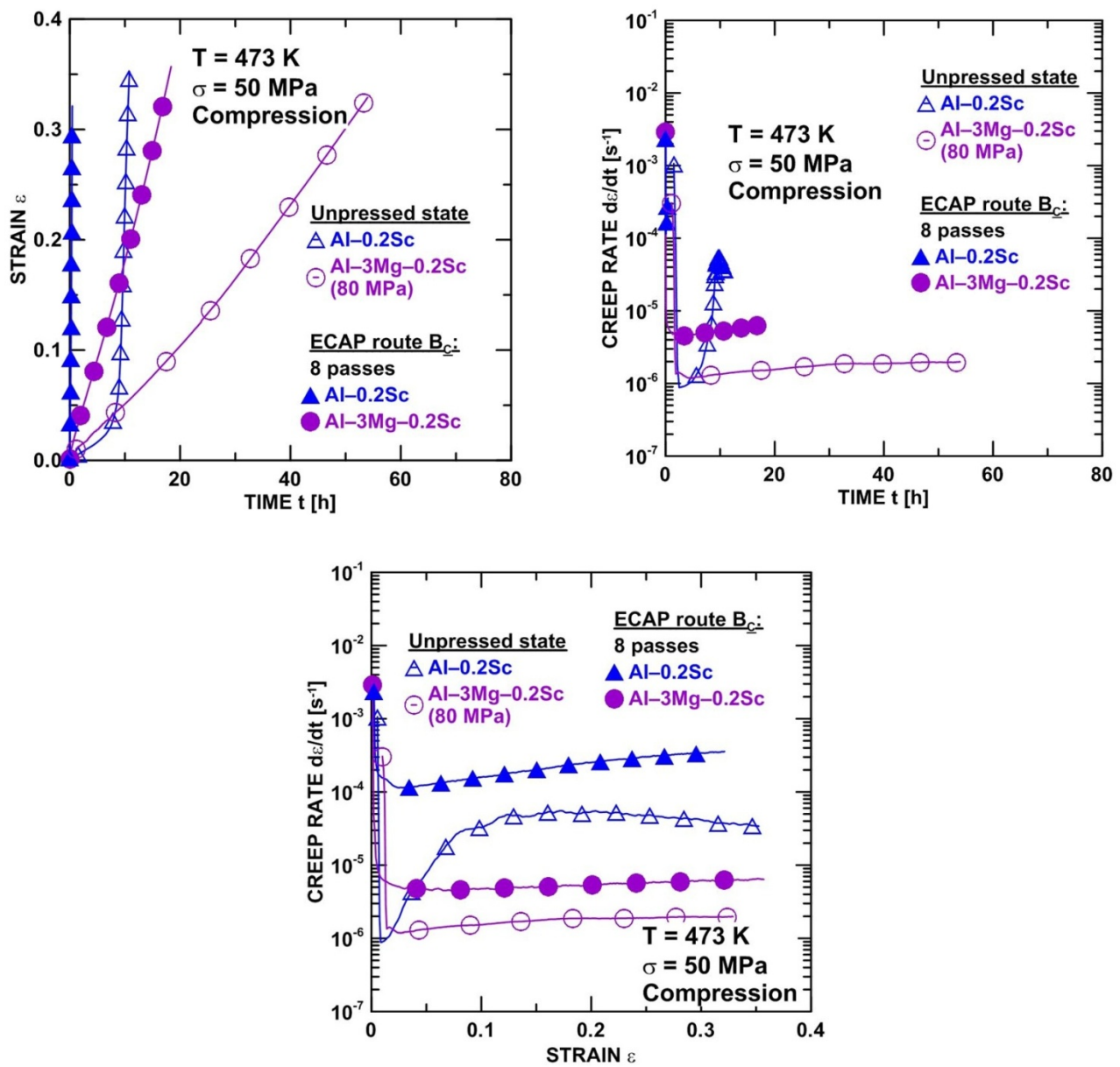

Figure 28. Creep curves for specimens after ECAP processing through 8 passes and for unpressed specimens: (a) standard creep curve, (b) creep rate vs. time, (c) creep rate vs. strain.

The differences in the minimum creep rates for pure $\mathrm{Al}, \mathrm{Al}-0.2 \mathrm{wt} . \% \mathrm{Sc}$ and $\mathrm{Al}-3 \mathrm{wt} . \% \mathrm{Mg}-0.2 \mathrm{wt}$. $\% \mathrm{Sc}$ in the as-received and as-pressed conditions are illustrated most readily in Figure 29 showing the variation of the minimum creep rate with applied stress. The results demonstrate that for pure aluminium at high stresses the minimum creep rate of ECAP material may be up 
to one order of magnitude lower than that of the unpressed material, although this difference decreases with decreasing applied stress so that, at $10 \mathrm{MPa}$ is negligible. By contrast, when tests of Al-Sc and Al-Mg-Sc alloys are performed at the same stress, the creep rates in the aspressed alloys are faster than in the unpressed alloys by more than two and/or three orders of magnitude on the strain rate scale. The stress dependence of the minimum creep rate for the aspressed Al-Mg-Sc alloy at lower stresses $(\sigma<20 \mathrm{MPa})$ is different in trend, which is clearly demonstrated by the characteristic curvature on the plot in Figure 29.

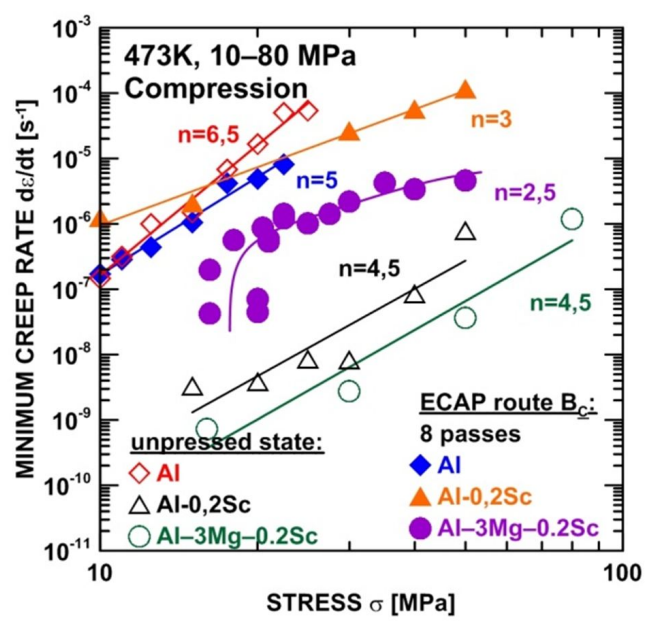

Figure 29. Stress dependences of minimum creep rate for pure aluminium and its alloys in the unpressed and ECAPed conditions.

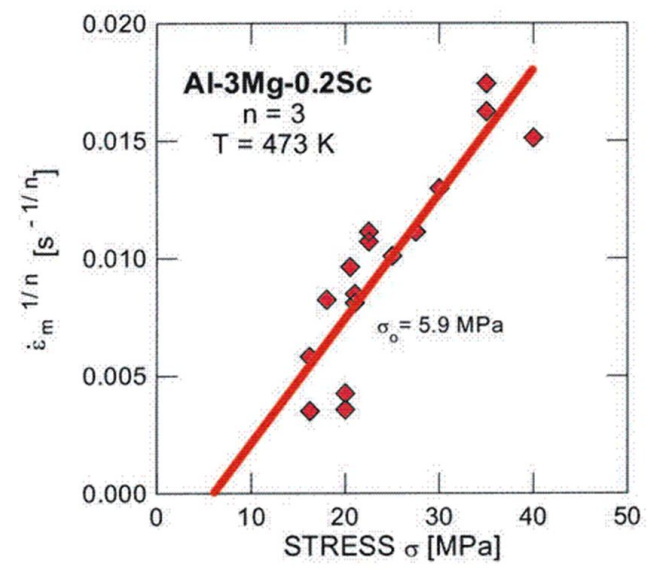

Figure 30. The linear extrapolation procedure for determining the threshold stress. 
Such behaviour is generally associated with the presence of a threshold stress marking a lower limit stress below which no measurable strain rate can be achieved [73,74]. The threshold stress value determined from linear plot [75] of $\dot{\varepsilon}^{1 / n}$ versus $\sigma$ is about $6 \mathrm{MPa}$ for the alloy studied. The validity of this approach is illustrated in Figure 30, where the data fall on straight line with the slope of 3, consistent with the assumed value of $\sim 3$ (Figure 29) for the stress exponent of the minimum creep rate $\mathrm{n}=\left(\partial \ln \dot{\varepsilon}_{\min } / \partial \ln \sigma\right)_{T}$.

Recently the tensile creep experiments on the same binary Al-0.2\%Sc alloy were reported [38]. The stress dependences of the minimum creep rates and the times to fracture for this alloy after 1 and 8 ECAP passes are shown in Figure 31. As demonstrates by Figure 31, the pressed alloy after 8 ECAP passes exhibits the very similar value of $n$ as the results obtained by compression tests (Figure 29).

\subsubsection{Creep deformation mechanisms}

The results from this investigation on precipitation-strengthened aluminium alloys do not confirm a general validity of the conclusion of our earlier results that processing by ECAP of a coarse-grained aluminium gave a potential for an improvement in the creep resistance [26,27]. By contrast, the Al-0.2wt.\%Sc and Al-3wt.\%Mg-0.2wt.\%Sc alloys exhibited faster creep rate than their coarse-grained counterparts when creep tested under the same loading conditions.
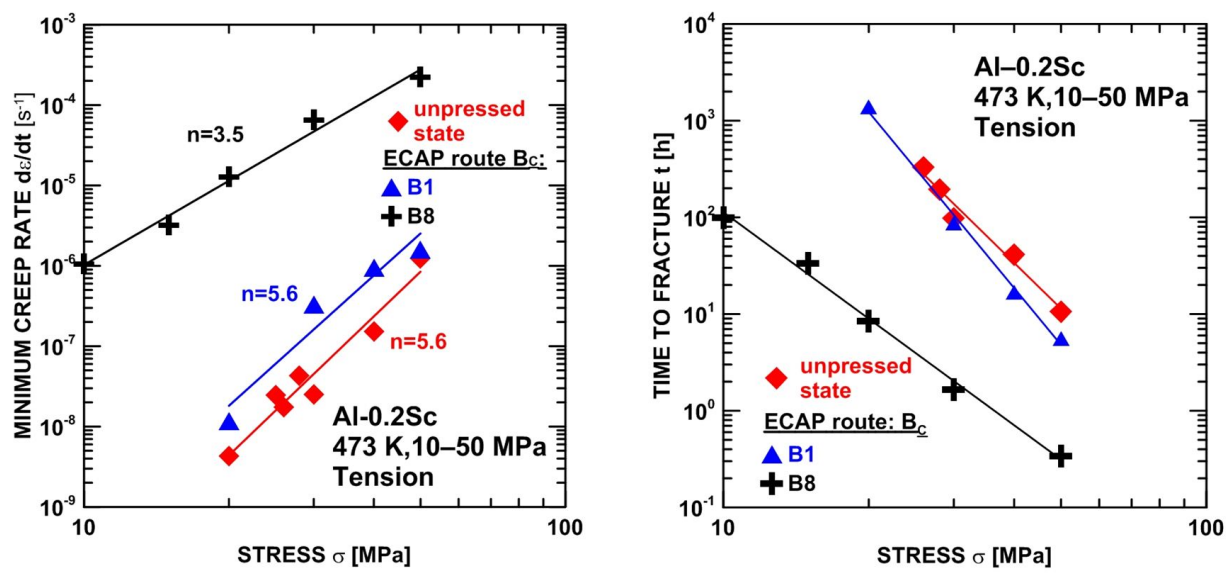

Figure 31. Stress dependence of (a) the minimum creep rates, and (b) times to fracture for Al-0.2Sc alloy.

The observed values of the stress exponents $n=(\partial \ln \dot{\varepsilon} / \partial \ln \sigma)_{T}$ are $\sim 4.5$ for the unpressed alloys and $\sim 3$ for the ECAPed alloys, respectively (see Figure 29). The mechanism which most probably plays the dominant role in the power-law creep $(\mathrm{n} \sim 4.5)$ of coarse-grained Al- $0.2 \mathrm{wt} . \% \mathrm{Sc}$ and Al-3wt.\%Mg-Sc alloys is the dislocation climb-bypass mechanism in the presence of elastic interactions between dislocations and coherent precipitates. The lower value of the stress 
exponent $(n \sim 3)$ found for the ECAPed alloys may reflect the synergetic effect of more intensive grain boundary sliding in the creep of ultrafine-grained materials [27]. Thus, an important contribution of grain boundary sliding to the total creep strain in the ultrafine-grained Al-0.2Sc and Al-3Mg-0.2Sc alloys may explain the observed detrimental effect of ECAP on their creep resistance. In order to examine rigorously the differences in creep behaviour of the alloys investigated more quantitative results of microstructural analysis are needed.

The detailed analysis was undertaken by Kawasaki et al. [36] to examine the flow characteristics of the ultrafined-grained Al-3Mg-0.2Sc and Al-0.2Sc alloys [33-35,43]. The theoretical predictions of the minimum creep rates have shown that Nabarro-Herring creep is too slow to account for the creep deformation in an ultrafine-grained Al-3wt.\%Mg-0.2wt.\%Sc alloy [33] but there is good agreement, to within an order of magnitude, with the predictions of superplastic flow except only at the lower stresses where the points deviate from linearity and there is evidence for the presence of a threshold stress (see Figure 29).This threshold stress probably arises from the presence of coherent $\mathrm{Al}_{3} \mathrm{Sc}$ precipitates.

For an Al-0.2wt.\%Sc alloy crept in compression at $473 \mathrm{~K}$ [33] predictions for Nabarro-Herring diffusional creep were again too slow but there was excellent agreement between the experimental datum points and the predicted behaviour in superplastic flow. The slightly higher stress exponent after ECAP may reflect an inhibition in GBS at the lowest strain rates due to the presence of intergranular $\mathrm{Al}_{3} \mathrm{Sc}$ precipitates. Finally, the results on an Al-0.2wt. $\%$ Sc alloy tested in creep under tensile conditions at $473 \mathrm{~K}$ [43] again shown that the predicted behaviour for Nabarro-Herring creep is too slow but there is reasonable agreement with the model for superplastic flow.

Thus, the results from both sets of experiments exhibit a general consistency with the predicted behaviour for conventional superplasticity. The theoretical predictions provide a clear demonstration that conventional creep mechanisms, already developed for coarsegrained materials, may be used to explain the flow characteristics of materials with ultrafine grain size. Furthemore, at least for the aluminium alloys examined in this Chapter, it is not necessary to involve any new and different creep deformation mechanisms.

\subsection{Creep ductility}

Creep ductility is very important for various shaping and forming technological operations at elevated and high temperatures and especially for avoiding catastrophic failure in load-bearing parts of high temperature components. Creep strength and ductility are the key creep properties of creep-resistant materials but these properties typically have opposing characteristics. Thus, these materials may be strong or ductile but they are rarely both. In this connection, recent findings of high strength and good ductility in several bulk ultrafine-grained (UFG) metals produced by severe plastic deformation (SPD) are of special interest [4].

Typically, creep ductility in tension which can be characterized by the strain to fracture $\varepsilon_{\mathrm{f}}$, is given by 


$$
\varepsilon_{f}(\sigma, T, S)=\int_{0}^{t_{f}(\sigma, T, S)} \dot{\varepsilon}(\sigma, T, S, t) d t
$$

where $\sigma$ is the applied stress, $\mathrm{T}$ is the absolute temperature, $\mathrm{S}$ is some parameter that characterizes the structure of specimen and $t_{f}$ is the time to fracture. According to the first meanvalue theorem of a definite integral eq. (4) can be expressed as

$$
\varepsilon_{f}(\sigma, T, S)=t_{f}(\sigma, T, S) \dot{\varepsilon}(\sigma, T, S)
$$

where $\dot{\varepsilon}(\sigma, T, S)$ is some strain rate in the interval from 0 to $\mathrm{t}_{\mathrm{f}}$.

A strong influence of the microstructure on creep behaviour has been observed in various UFG materials $[22,23,38,49,54,76]$. By contrast, no report is available describing the link between microstructure and creep ductility in UFG materials processed by ECAP at elevated and high temperatures.

To investigate a course of creep strain during creep exposure and for mutual comparison of the fracture strains Figures 32a and 33a can be replotted in the form of the instantaneous strain rate $\mathrm{d} \varepsilon / \mathrm{dt}$ versus creep exposure time $\mathrm{t}$ normalized to the time to fracture $\mathrm{t}_{\mathrm{f}}$ as shown in Figures 32b and 33b. The figures demonstrate that very significant strain contributions to the fracture strains are generated during the last tenth of creep life, however, an accumulation of the creep strains during the course of creep exposure slightly differ.
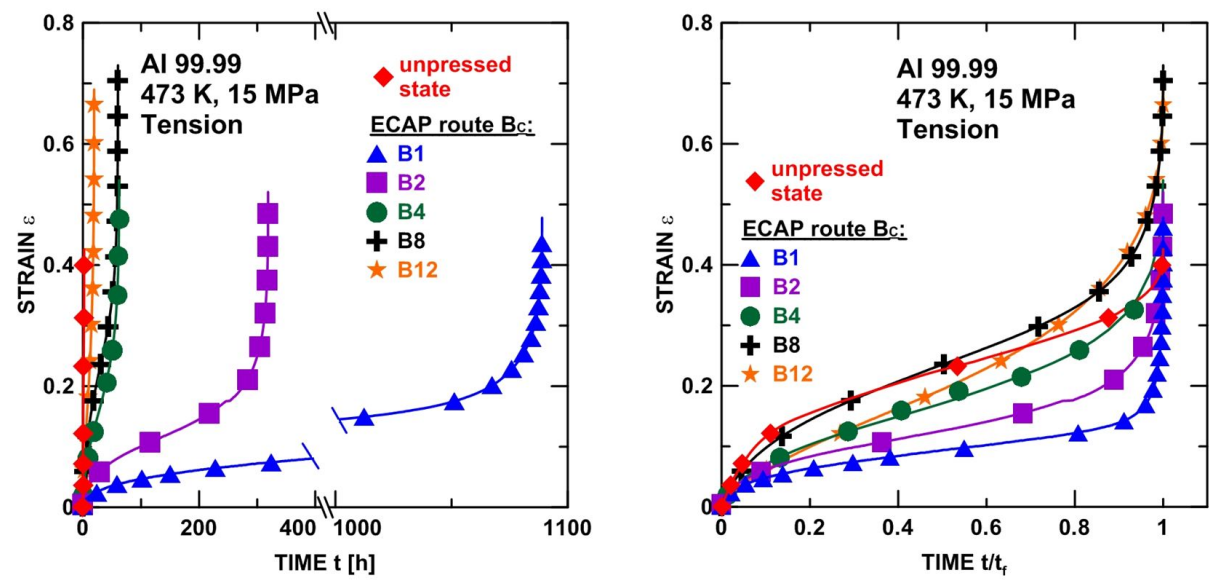

Figure 32. Creep curves of pure aluminium for unpressed state and various number of ECAP passes (creep in tension up to fracture): (a) standard creep curves, (b) creep strain $\varepsilon$ vs. time $t / t_{f}$.

A question naturally arises about an approach to the problem of creep ductility enhancement. In this connection different approaches may be considered [4]. It has been suggested that some ductility enhancement may be associated with an increase in the fraction of high- 
angle grain boundaries with increasing number ECAP passes and with a consequent change in the controlling deformation mechanisms due to the increasing tendency for the occurrence of grain boundary sliding. A possible explanation for the occurrence of intensive grain boundary sliding in UFG materials is that diffusion is more rapid in ECAP processed materials with highly non-equilibrium grain boundaries [77,78]. Accordingly, it appears that grain boundary sliding is easier in these UFG materials during creeping at ambient temperatures leading to the possibility of increased ductility. Figure 34a shows the measured strain to fracture as a function of the fraction of HAGBs when testing under creep loading conditions presented in Figures 32 and 33.
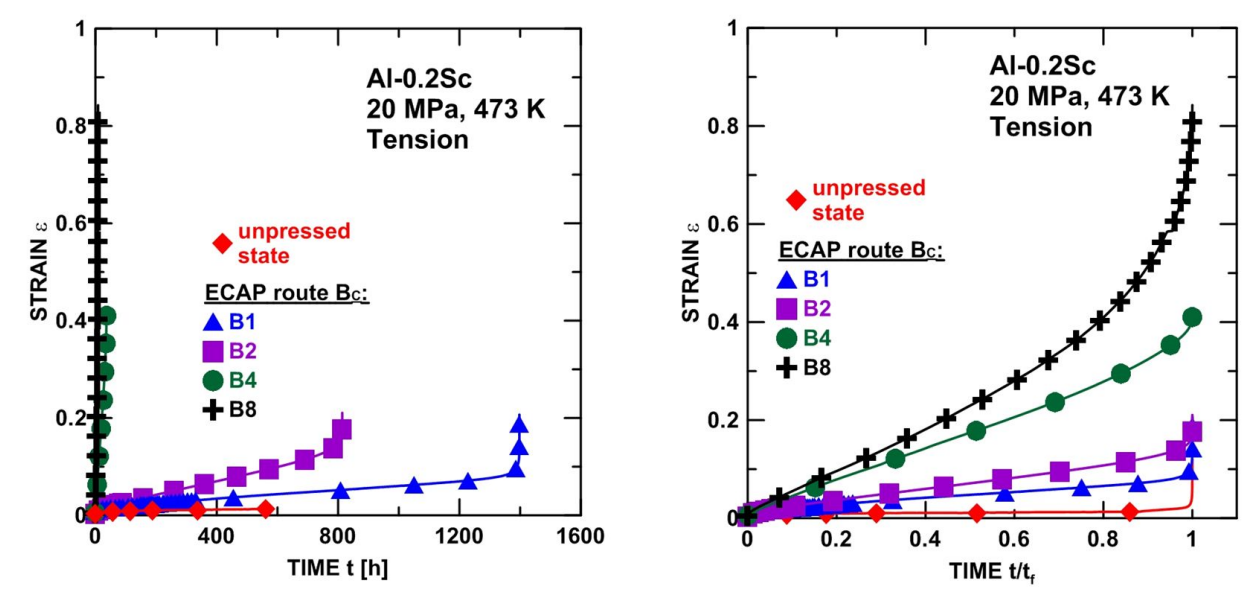

Figure 33. Creep curve of an Al-0.2wt.\%Sc alloy for unpressed state and various number of ECAP passes (creep in tension up to fracture): (a) standard creep curves, (b) creep strain $\varepsilon$ vs. time $t / t_{f}$.

It is apparent from Figure 34a that specimens with higher fraction of high-angle grain boundaries exhibit higher ductility. Further approach to the problem of ductility enhancement at room temperature in ultrafine-grained materials was suggested through the introduction of a bimodal or multi-modal grain size distribution [79-81]. In this ductility strategy, the ultrafine-grained matrix in the bimodal microstructure provides the high strength, while the relatively large grains of the order of micrometers contribute to the ductility. The existence of large grains may also release stress concentrations, thereby delay the early fracture of the specimens, and allow further plastic deformation to take place in the ultrafine-grained matrix. Furthermore, the investigation of copper showed that bimodal structures may increase the ductility not only during tensile testing but also during cyclic deformation [82].

Unfortunately, the results of this work have not advocated the advantages of using material with a bimodal and/or multimodal grain size distribution for obtaining at the same time good creep strength and ductility at elevated or high temperatures. As it follows by inspection of Figures 19 and 20 typical feature of the boundary structure of UFG materials is its inhomogeneity; especially at low values of ECAP passes N completely different structures are observed. The dispersion of observed grain profile areas attains quite enormous values of the coefficient 
of variation $\mathrm{CV}_{\mathrm{a}}$ (between 6 to 16) in the whole range of $\mathrm{N} \leq 12$. In such circumstances, a great variability of times to fracture and creep fracture strain is a natural consequence of short as well as long-range inhomogeneity of microstructure of tested specimens. A very pronounced improvement of creep ductility and strong evidence for a significant role of microstructure homogeneity are documented in Figure 34b. These data indicate possible relationship between the ECAP microstructure and the creep ductility of the pressed materials [48]. The better is homogeneity of pressed material the better is its creep ductility. Thus, using a non-uniform grain structure by mixing ultrafine - sized and larger grains to derive enhanced ductility [83] seems not to be beneficial at elevated and/or high temperatures.
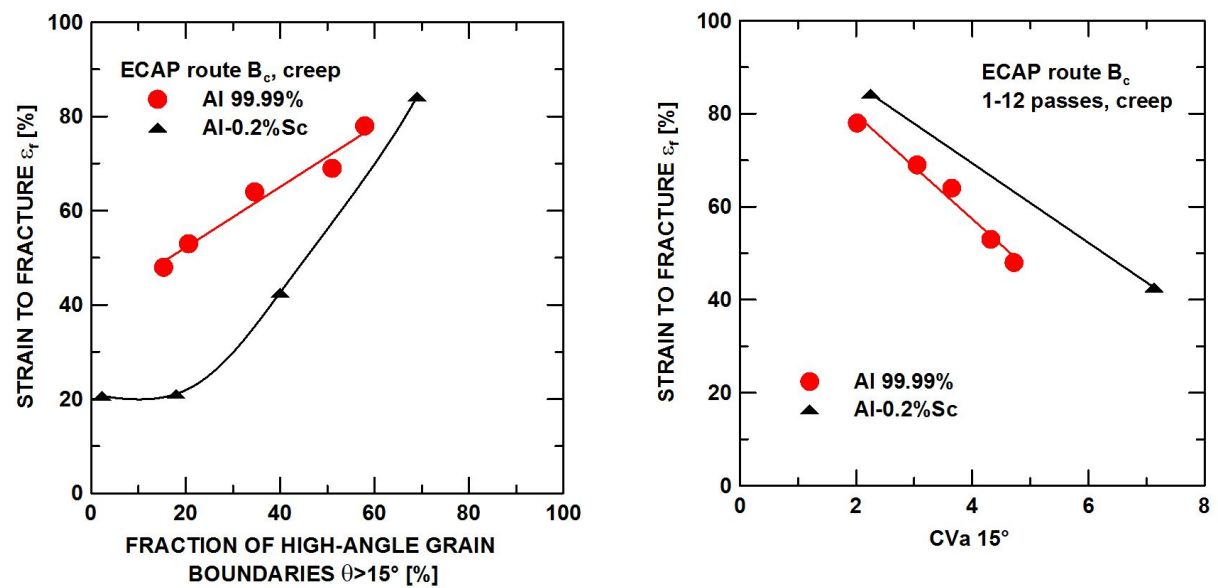

Figure 34. Dependence of the strain to fracture $\varepsilon_{f}$ on (a) the fraction of high-angle grain boundaries $\theta>15^{\circ}$, and (b) on the coefficient CVa for EBSD range $\Delta \geq 15^{\circ}$. Crept at $473 \mathrm{~K}$ and $15 \mathrm{MPa}$ (Al 99.99\%) or $20 \mathrm{MPa}(\mathrm{Al}-0.2 \% \mathrm{Sc})-$ see Figures 32 and 33.

Finally, due to a frequent use of miniaturized tensile specimens in research on UFG materials the specimen dimension and/or geometry effects could be considered for ductile behaviour of these materials. Thus, the thickness effect is mainly caused by the necking geometry and/or fracture modes, and the gauge length effect originates from the strain definition [84]. Therefore, no existence of a standardized protocol of creep specimen and a great variety of specimen sizes and geometries have been used by different authors, primarily depending on SPD techniques used and on the availability of material. Thus, the results creep ductile behaviour measured using such different specimens are hardly comparable.

\section{Conclusions}

High purity $(4 \mathrm{~N})$ aluminium, a ternary Al-3wt.\%Mg-0.2wt.\%Sc and a binary Al- $0.2 \mathrm{wt} . \% \mathrm{Sc}$ alloys were processed by equal-channel angular pressing (ECAP) through 1-12 passes and examined by TEM, SEM and EBSD microscopy. The microstructural investigations reveal 
that from 1 to 4 ECAP passes the microstructure evolves from elongated subgrains to an essentially equiaxed array of ultrafine grains $(\mathrm{d}<1 \mu \mathrm{m})$ and from 4 to 12 passes there is no substantial change in average grain size. The boundary misorientation angle and the fraction of high-angle grain boundaries (HAGBs) increase rapidly up to 4 ECAP passes and at a slower rate from 4 to 12 passes.

It was found, that the creep resistance of pure aluminium is considerably increased in comparison with the coarse-grained unpressed state already after first ECAP pass. However, successive ECAP pressing lead to a noticeable decrease in the creep properties. This softening may be related to the decrease of the spacing of HAGBs at approximately constant subgrain size with increasing number of ECAP passes, resulting in the fraction of low-angle boundaries decreasing considerably. This indicates that HAGBs have lower strengthening effect under creep than low-angle ones. The softening by HAGBs may be explained in terms of the indirect effect which grain boundaries exert on the creep resistance by influencing the evolution of the dislocation microstructure in modifying the rates of generation and annihilation of dislocations. Further, a progressively increasing contribution of grain boundary sliding along HAGBs to overall creep strain can be expected as a consequence of accompanying transformation of low angle boundaries towards an equilibrium state when the number of passes increases. The results demonstrate that creep occurs in pure aluminium after processing by ECAP by the same mechanism as in conventional coarse-grained materials with intragranular dislocation glide and climb as the dominant rate-controlling deformation processes. Therefore, the higher creep resistance of pressed aluminium cannot be a consequence of any significant change in the rate controlling process.

The present results concerning Al-3wt.\%Mg-0.2wt.\%Sc and Al-0.2wt.\%Sc alloys do not confirm a general validity of the conclusion that processing by ECAP of a coarse-grained material gives a potential for an improvement in the creep resistance. By contrast, the minimum creep rates for the pressed alloys are more rapid than the rate attained in the coarse-grained state. The creep mechanism which most probably plays the dominant role in creep of the coarsegrained alloys is the dislocation climb-bypass mechanism in the presence of elastic interaction between dislocations and coherent $\mathrm{Al}_{3} \mathrm{Sc}$ precipitates. Strong support for making use of the same conventional creep mechanism in interpreting the creep characteristic of pressed alloy was presented. Although it seems acceptable to associate these faster creep rates with the smaller grain size after ECAP due to more intensive grain boundary sliding, there are probable further reasons strongly influencing an intragranular deformation mechanism which seems to be the rate-controlling process. First, the pressed alloys contain a high dislocation density because of the intense straining imposed during pressing. Second, an important strain contribution during creep of pressed alloys is produced by intensive mesoscale sliding of groups of grains along shear bands. Finally, the occurrence of nanopores formed during ECAP pressing at matrix/precipitate interfaces and resulting in the decohesion at coherent particle surface could have a strong effect on the creep behaviour of pressed alloys. It is important to note that the experimental results are in reasonable agreement with a theoretical model for superplastic flow that was developed earlier for coarse-grained alloys. This conclusion is important because of the many results now available demonstrating the occurrence of superplastic elonga- 
tions in materials processed by ECAP and because of the new possibilities for achieving exceptional superplastic elongations in materials with ultrafine grain sizes.

\section{Acknowledgements}

The authors acknowledge the financial support for this work by the Czech Science Foundation under the Grant No. P108/11/2260. This work was realized in CEITEC - Central European Institute of Technology with research infrastructure supported by the project CZ. 1.05/1.1.00/02.0068 financed from European Regional Development Fund. We would like to cordially thank late Dr. Ivan Saxl of Mathematical Institute of the Academy of Sciences of the Czech Republic for his useful advices concerning the correct applications and interpretations of strereological methods for quantitative characterization of microstructure.

\section{Author details}

Vaclav Sklenicka $^{1,2^{*}}$, Jiri Dvorak ${ }^{1,2}$, Milan Svoboda $^{1,2}$, Petr Kral ${ }^{1}$ and Marie Kvapilova ${ }^{1}$

*Address all correspondence to: V. Sklenicka, sklen@ipm.cz

1 Institute of Physics of Materials Academy of Sciences of the Czech Republic, Brno, Czech Republic

2 CEITEC-IPM, Institute of Physics of, Materials, Academy of Sciences of the Czech Republic, Brno, Czech Republic

\section{References}

[1] Valiev, R. Z. (2011). Producing Bulk Nanostructured Metals and Alloys by Severe Plastic Deformation (SPD). In: Whang S H, editor. Nanostructured Metals and Alloys: Processing, Microstructure, Mechanical Properties and Applications, Cambridge, Woodhead Publishing Ltd., 3-39.

[2] Erb, U., Palumbo, G., \& McCrea, J. L. (2011). The Processing of Bulk Nanocrystalline Metals and Alloys by Electrodeposition. In: Whang $S$ H, editor. Nanostructured Metals and Alloys: Processing, Microstructure, Mechanical Properties and Applications, Cambridge, Woodhead Publishing Ltd., 118-177.

[3] Valiev, R. Z., Islamgaliev, R. K., \& Alexandrov, I. V. (2000). Bulk Nanostructured Materials from Severe Plastic Deformation. Progr Mater Sci, 45, 103-189.

[4] Valiev, R. Z., \& Langdon, T. G. (2006). Principles of Equal-Channel Angular Pressing as a Processing Tool for Grain Refinement. Progr Mater Sci, 51, 881-981. 
[5] Zhu, Y. T., Valiev, R. Z., Langdon, T. G., Tsuji, N., \& Lu, K. (2010). Processing of Nanostructured Metals and Alloys via Plastic Deformation. MRS Bulletin, 35, 977-981.

[6] Valiev, R. Z., \& Langdon, T. G. (2011). Achieving Exceptional Grain Refinement Through Severe Plastic Deformation: New Approaches for Improving the Processing Technology. Metall Mater Trans, 42, 2942-2951.

[7] Nakashima, K., Horita, Z., Nemoto, M., \& Langdon, T. G. (2000). Development of a Multi-Pass Facility for Equal-Channel Angular Pressing to High Total Strains. Mater Sci Eng A, 281, 82-87.

[8] Furukawa, M., Iwahashi, Y., Horita, Z., Nemoto, M., \& Langdon, T. G. (1998). The Shearing Characteristics Associated with Equal-Channel Angular Pressing. Mater Sci Eng A, 257, 328-332.

[9] Iwahashi, Y., Horita, Z., Nemoto, M., \& Langdon, T. G. (1998). The Process of Grain Refinement in Equal-Channel Angular Pressing. Acta Mater, 46, 3317-3331.

[10] Mc Nelley, T. R., Swisher, D. L., Horita, Z., \& Langdon, T. G. (2002). Influence of Processing Route on Microstructure and Grain Boundary Development During Equal-Channel Angular Pressing of Pure Aluminium. In: Zhu Y T et al., Ultrafine Grained Materials II, Warrendale, TMS, 15-24.

[11] Sklenicka, V., Dvorak, J., Svoboda, M., Kral, P., \& Vlach, B. (2005). Effect of Processing Route on Microstructure and Mechanical Behaviour of Ultrafine-Grained Metals Processed by Severe Plastic Deformation. Mater Sci Forum, 482, 83-88.

[12] Dvorak, J., Sklenicka, V., \& Horita, Z. (2008). Microstructural Evolution and Mechanical Properties of High Purity Aluminium Processed by Equal-Channel Angular Pressing. Mater Trans, 49, 15-19.

[13] Betekhtin, V. I., Kadomtsev, A. G., Sklenicka, V., \& Saxl, I. (2007). Nanoporosity of Fine-Crystalline Aluminium and an Aluminium-Based Alloy. Phys Solid State, 49, 1787-1790.

[14] Betekhtin, V. I., Kadomtsev, A. G., Kral, P., Dvorak, J., Svoboda, M., Saxl, I., \& Sklenicka, V. (2007). Significance of Microdefects Induced by ECAP in Aluminium, Al-0.2\%Sc Alloy and Copper. Mater Sci Forum, 567-568, 93-96.

[15] Betekhtin, V. I., Sklenicka, V., Saxl, I., Kardashev, B. K., Kadomtsev, A. G., \& Narykova, M. V. (2010). Influence of the Number of Passes under Equal-Channel Angular Pressing on the Elastic-Plastic Properties, Durability, and Defect Structure of the Al-0.2wt\%Sc Alloy. Phys Solid State, 52, 1517-1523.

[16] Betekhtin, V. I., Kadomtsev, A. G., Sklenicka, V., \& Narykova, M. V. (2011). Effect of Hydrostatic Pressure on Defect Structure and Durability of Ultrafine-Grained Aluminium. Tech Phys Letters, 37, 977-979. 
[17] Betekhtin, V. I., Kadomtsev, A. G., \& Kardashev, B. K. (2006). Elasticity and Anelasticity of Microcrystalline Aluminum Samples Having Various Deformation and Thermal History. Phys Solid State, 48, 1506-1512.

[18] Betekhtin, V. I., Tabachnikova, E. D., Kadomtsev, A. G., Narykova, M. V., \& Lapovok, M. V. (2011). Effect of Counterpressure During Equal-Channel Angular Pressing on Nanoporosity Formation in Ultrafine-Grained Copper. Tech Phys Letters, 37, 767-768.

[19] Kolobov, Yu. R., \& Ratochka, J. V. (2005). Grain Boundary Diffusion and Plasticity/ Superplasticity of Polycrystalline and Nanostructured Metals and Alloys. Mater Sci Eng A, 410- 411, 468-471.

[20] Humphreys, F. J. (2001). Grain and Subgrain Characterization by Electron Backscatter Diffraction. J Mater Sci, 36, 3833-3854.

[21] Ilucova, 1., Saxl, I., Svoboda, M., Sklenicka, V., \& Kral, P. (2007). Structure of ECAP Aluminium after Different Number of Passes. Image Anal Stereol, 26, 37-43.

[22] Saxl, I., Sklenicka, V., Ilucova, L., Svoboda, M., Dvorak, J., \& Kral, P. (2009). The Link Between Microstructure and Creep in Aluminium Processed by Equal-Channel Angular Pressing. Mater Sci Eng A, 503, 82-85.

[23] Saxl, I., Kalouskova, A., Ilucova, L., \& Sklenicka, V. (2009). Grain and Subgrain Boundaries in Ultrafine-Grained Materials. Mater Characterization, 60, 1163-1167.

[24] Gao, N., Wang, S., Ubhi, H. S., \& Starink, M. A. (2005). A Comparison of Grain Size Determination by Light Microscopy and EBSD Analysis. J Mater Sci, 40, 4971-4974.

[25] Sklenicka, V., Dvorak, J., \& Svoboda, M. (2004). Creep Behaviour of Pure Aluminium Processed by Equal-Channel Angular Pressing. In: Zehetbauer M J, Valiev R Z, editors. Nanomaterials by Severe Plastic Deformation, Weinham, Wiley VCH, 200-206.

[26] Sklenicka, V., Dvorak, J., \& Svoboda, M. (2004). Creep in Ultrafine-Grained Aluminium. Mater Sci Eng A, 387-389, 696-701.

[27] Sklenicka, V., Dvorak, J., Kral, P., Stonawska, Z., \& Svoboda, M. (2005). Creep Processes in Pure Aluminium Processed by Equal-Channel Angu-lar Pressing. Mater Sci Eng A, 410-411, 408-412.

[28] Venkateswarlu, K., Rajinikanth, V., Ray, A. K., Xu, C., \& Langdon, T. G. (2010). The Characteristics of Aluminum-Scandium Alloys Processed by ECAP. Mater Sci Eng A, $527,1448-1452$.

[29] Royset, J., \& Ryum, N. (2005). Kinetics and Mechanisms of Precipitation in an Al-0.2wt.\%Sc Alloy. Mater Sci Eng A, 396, 409-422.

[30] Furukawa, M., Utsunomiya, A., Matsubara, K., Horita, Z., \& Langdon, T. G. (2001). Influence of Magnesium on Grain Refinement and Ductility in a Dilute Al-Sc Alloy. Acta Mater, 49, 3829-3838. 
[31] Marquis, E., Seidman, D. N., \& Dunand, D. C. (2003). Effect of Mg Addition on the Creep and Yield Behaviour of an Al-Sc Alloy. Acta Mater, 51, 4751-4760.

[32] Komura, S., Horita, Z., Furukawa, M., Nemoto, M., \& Langdon, T. G. (2001). An Evaluation of the Flow Behavior During High Strain Rate Superplasticity in an Al-Mg-Sc Alloy. Metall Mater Trans A, 32, 707-716.

[33] Sklenicka, V., Dvorak, J., Svoboda, M., Kral, P., Kvapilova, M., \& Horita, Z. (2006). Compressive Creep in an Al-3\%Mg-0.2\%Sc Alloy Processed by Equal-Channel Angular Pressing. In: Zhu Y, Langdon T G, Horita Z, Zehetbauer M J, Semiatin S L, Lowe T C, editors. Ultrafine Grained Materials IV, Warrendale, TMS, 459-464.

[34] Sklenicka, V., Dvorak, J., Kvapilova, M., Svoboda, M., Kral, P., Saxl, I., \& Horita, Z. (2007). Effect of Equal-Channel Angular Pressing (ECAP) on Creep in Aluminium Alloys. Mater Sci Forum, 539-543, 2904-2909.

[35] Kral, P., Dvorak, J., \& Sklenicka, V. (2008). Microstructural Evolution and Creep of an Al-0.2wt.\%Sc Alloy After Equal-Channel Angular Pressing. Mater Sci Forum, 584-586, 846-851.

[36] Kawasaki, M., Sklenicka, V., \& Langdon, T. G. (2010). An Evaluation of Creep Behavior in Ultrafine-Grained Aluminum Alloys Processed by ECAP. J Mater Sci, 45, 271-274.

[37] Kawasaki, M., Sklenicka, V., \& Langdon, T. G. (2011). Creep Behavior of Metals Processed by Equal-Channel Angular Pressing. Kovove Mater, 49, 75-83.

[38] Marquis, E. A., \& Seidman, D. N. (2001). Nanoscale Structural Evolution of $\mathrm{Al}_{3} \mathrm{Sc}$ Precipitates in $\mathrm{Al}(\mathrm{Sc})$ Alloys. Acta Mater, 49, 1909-1919.

[39] Sklenicka, V., Kral, P., Dvorak, J., Kvapilova, M., Kawasaki, M., \& Langdon, T. G. (2011). Effect of Equal-Channel Angular Pressing on the Creep Resistance of Precipitation-Strengthened Alloys. Mater Sci Forum, 667-669, 897-902.

[40] Hahn, H., Mondal, P., \& Podmanabhan, K. (1997). Plastic Deformation of Nanocrystalline Materials. NanoStruc Mater, 9, 603-607.

[41] Vinogradov, A., Hashimoto, S., Patlan, V., \& Kitagawa, K. (2001). Atomic Force Microscopic Study on Surface Morphology of Ultra-Fine Grained Materials After Tensile Testing. Mater Sci Eng A, 319-321, 862-866.

[42] Huang, Y., \& Langdon, T. G. (2003). Using Atomic Force Microscopy to Evaluate the Development of Mesoscopic Shear Planes in Materials Processed by Severe Plastic Deformation. Mater Sci Eng A, 358, 114-121.

[43] Sklenicka, V., Dvorak, J., Kral, P., Svoboda, M., \& Saxl, I. (2009). Some Factors Affecting the Creep Behaviour of Metallic Materials Processed by Equal-Channel Angular Pressing. Int J Mat Res, 100, 762-766.

[44] Prochazka, J., Ponizil, P., \& Saxl, I. (2008). Grain Size Estimation in Anisotropic Materials. Mater Sci Forum, 567- 568, 285-288. 
[45] Saxl, I., \& Sklenicka, V. (2009). Interpretation of Profile and Intercept Counts in Microstructure Characterization. Mater Sci Forum, 604-605, 403-410.

[46] Kral, P., Dvorak, J., Kvapilova, M., Benes, V., Ponizil, P., Sedivy, O., \& Sklenicka, V. (2011). Quantitative Characterization of Microstructure in Copper Processed by Equal-Channel Angular Pressing. Mater Sci Forum, 667-660, 235-240.

[47] Saxl, I., Sulleiova, K., \& Ponizil, P. (2001). Simulating Grain Size Estimation. Kovove Mater, 39, 396-409.

[48] Sklenicka, V., Kral, P., Ilucova, L., Saxl, I., Dvorak, J., \& Svoboda, M. (2006). Inhomogeneity of Microstructure and Creep of ECAP Aluminium. Mater Sci Forum, 503-504, 245-250.

[49] Sklenicka, V., Dvorak, J., Kral, P., Svoboda, M., Kvapilova, M., \& Langdon, T. G. (2012). Creep Ductility of Ultrafine-Grained Metallic Materials. Submited to Mat Sci Eng $A$.

[50] Kapoor, R., Kumar, N., Mishra, R. S., Huskamp, C. S., \& Sankaran, K. K. (2010). Influence of Fraction of High Angle Boundaries on the Mechanical Behavior of an Ultrafine Grained Al-Mg Alloy. Mater Sci Eng A, 527, 5246-5254.

[51] Phaniraj, M. P., Prasad, M. J. N. V., \& Chokshi, A. H. (2007). Grain-Size Distribution Effects in Plastic Flow and Failure. Mater Sci Eng A, 463, 231-237.

[52] Hasegawa, H., Komura, S., Utsunomiya, A., Horita, Z., Furukawa, M., Nemoto, M., \& Langdon, T. G. (1999). Thermal Stability of Ultrafine-Grained Aluminium in the Presence of Mg and Zr Additions. Mater Sci Eng A, 265, 188-196.

[53] Mughrabi, H., Höppel, H. W., Kautz, M., \& Valiev, R. Z. (2003). Annealing Treatments to Enhance Thermal and Mechanical Stability of Ultrafine-Grained Metals Produced by Severe Plastic Deformation. Z Metallkde, 94, 1079-1083.

[54] Kawasaki, M., Beyerline, I. J., Vogel, S. C., \& Langdon, T. G. (2008). Characterization of Creep Properties and Creep Textures in Pure Aluminum Processed by EqualChannel Angular Pressing. Acta Mater, 56, 2307-2317.

[55] Wilshire, B., \& Palmer, C. (2002). Deformation Processes During Creep of Pure Aluminium. In: Mishra R S, Earthman J C, Raj S V, editors. Creep Deformation. Fundamentals and Applications, Warrendale, TMS, 51-60.

[56] Wilshire, B., \& Scharning, P. J. (2008). Creep and Creep Fracture of Commercial Aluminium Alloys. J Mater Sci, 43, 3992-4000.

[57] Sklenicka, V., Dvorak, J., \& Svoboda, M. (2004). Influence of Processing Route on Creep of Ultrafine Grained Aluminium Prepared by ECAP. In: Zhu Y T, Langdon T G, Valiev R Z, Semiatin S L, Shin D H, Lowe T C, editors. Ultrafine Grained Materials III, Warrendale, TMS, 647-652.

[58] Sklenicka, V., \& Cadek, J. (1970). Determination of Strain Component Caused by Grain Boundary Sliding. Z Metallkde, 61, 575-580. 
[59] Cadek, J. (1988). Creep in Metallic Materials, Amsterdam, Elsevier Science Publ., 372.

[60] Langdon, T. G. (2006). Grain Boundary Sliding Revisited. Developments in Sliding over Four Decades. J Mater Sci, 41, 597-609.

[61] Zhilyaev, A., \& Pshenichnyuk, A. (2011). Superplasticity and Grain Boundaries in Ultrafine-Grained Materials, Cambridge, Woodhead Publishing, 312.

[62] Divinski, S. V., Reglitz, G., Rosner, H., Estrin, Y., \& Wilde, G. (2011). Ultra-Fast Diffusion Channels in Pure Ni Severly Deformed by Equal-Channel Angular Pressing. Acta Mater, 59, 1974-1985.

[63] Nabarro, F. R. N. (1948). Deformation of Crystals by the Motions of Single Ions. In: Rep. Conf. Strength Solids, The Physical Society London, 75.

[64] Herring, C. (1950). Diffusional Viscosity of a Polycrystalline Materials. J Appl Phys, $21,437$.

[65] Coble, R. L. (1963). A Model for Boundary Diffusion Controlled Creep in Polycrystalline Materials. J Appl Phys, 31, 1679.

[66] Mohamed, F. A., \& Langdon, T. G. (1974). Deformation Mechanism Maps Based on Grain-Size. Metall Trans, 5, 2239-2345.

[67] Zeng, X. H., Li, Y. J., \& Blum, W. (2004). On Coble Creep in Ultrafine-Grained Cu. Phys Stat Sol (a), 201(14), R114-117.

[68] Yavari, P., Mohamed, F. A., \& Langdon, T. G. (1981). Creep and Substructure Formation in an Al-5Percent Mg Solid Solution Alloy. Acta Metall, 29, 1495-1507.

[69] Yavari, P., \& Langdon, T. G. (1982). An Examination of the Breakdown in Creep by Viscous Glide in Solid Solution Alloys at High Stress Levels. Acta Metall, 30, 2181-2196.

[70] Mc Nelley, T. R., Michel, D. J., \& Salama, A. (1989). The Mg-Concentration Dependence of the Strength of AlMg Alloys During Glide-Controlled Deformation. Scripta Met, 23, 1657-1662.

[71] Fuller, C. B., Seidman, D. N., \& Dunand, D. C. (1999). Creep Properties of CoarseGrained $\mathrm{Al}(\mathrm{Sc})$ Alloys at $300^{\circ} \mathrm{C}$. Scripta Mater, 40, 691-696.

[72] Seidman, D. N., Marquis, E. A., \& Dunand, D. C. (2002). Precipitation Strengthening at Ambient and Elevated Temperatures of Heat-Treatable $\mathrm{Al}(\mathrm{Sc})$ Alloys. Acta Mater, 50, 4021-4035.

[73] Gibeling, J. C., \& Nix, W. D. (1980). The Description of Elevated Temperature Deformation in Terms of Threshold Stresses and Back Stresses: A Review. Mater Sci Eng, 45, 123-135.

[74] Marquis, E. A., \& Dunand, D. C. (2002). Model for Creep Threshold Stress in Precipitation-Strengthened Alloys with Coherent Particles. Scripta Mat, 47, 503-508. 
[75] Cadek, J., Zhu, S. J., \& Milicka, K. (1998). Threshold Creep Behaviour of Aluminium Dispersion Strengthened by Fine Alumina Particles. Mater Sci Eng A, 252, 1-5.

[76] Blum, W., Eisenlohr, P., \& Sklenicka, V. (2009). Creep Behavior of Bulk Nanostructured Materials- time dependent deformation and deformation kinetics. In: Zehetbauer M J, Zhu T Z, editors. Bulk Nanostructured Materials, Weinhaim, Wiley-VCH Verlag GmBH \& Co., 519-538.

[77] Kolobov, Y. R., Grabovetskaya, G. P., Ivanov, M. B., Zhilyaev, A. P., \& Valiev, R. Z. (2001). Grain Boundary Diffusion Characteristics of Nanostructured Nickel. Scripta Mater, 44, 873-878.

[78] Wang, Z. B., Lu, K., Wilde, G., \& Divinski, S. V. (2011). Effect of Grain Growth on Interface Diffusion in Nanostructured Cu. Scripta Mater, 64, 1055-1058.

[79] Wang, Y., Chen, M., Zhou, F., \& Ma, E. (2002). High Tensile Ductility in a Nanostructured Metal. Nature, 419, 912-914.

[80] Kawasaki, M., Horita, Z., \& Langdon, T. G. (2009). Microstructural Evolution in High Purity Aluminum Processed by ECAP. Mater Sci Eng A, 524, 143-150.

[81] Llorca-Isern, N., Grosdidier, T., \& Cabrera, J. M. (2010). Enhancing Ductility of ECAP Pressed Metals. Mater Sci Forum, 654-656, 1219-1222.

[82] Korn, M., Lapovok, R., Böhner, A., Höppel, H. W., \& Mughrabi, H. (2011). Bimodal Grain Size Distributions in UFG Materials Produced by SPD- Their Evolution and Effect on the Fatigue and Monotonic Strength Properties. Kovove Mater, 49, 51-53.

[83] Ma, E. (2003). Instabilities and Ductility of Nanocrystalline and Ultrafine-Grained Metals. Scripta Mater, 49, 663-668.

[84] Zhao, Y. H., Guo, Y. Z., Wie, Q., Dangelewitz, A. M., Xu, C., Zhu, Y. T., Langdon, T. G., Zhou, Y. Z., \& Lavernia, E. J. (2008). Influence of Specimen Dimensions on the Tensile Behaviour of Ultrafine-Grained Cu. Scripta Mater, 59, 627-630. 
